\title{
Melastomataceae endémicas del Perú
}

\author{
Blanca León ${ }^{1,2}$
}

${ }^{1}$ Museo de Historia Natural, Av. Arenales 1256, Aptdo. 14-0434, Lima 14, Perú

2 Plant Resources Center, University of Texas at Austin, Austin TX 78712 EE.UU.

blanca.leon@mail.utexas.edu

\section{Resumen}

La familia Melastomataceae es reconocida en el Perú con 43 géneros y 660 especies (Brako \& Zarucchi, 1993; Ulloa Ulloa et al., 2004), principalmente arbustos y árboles. En este trabajo reconocemos 169 especies y 13 taxones subespecíficos como endemismos, en 26 géneros. El género Miconia incluye el mayor número de especies endémicas. Las Melastomataceae endémicas se encuentran principalmente en las regiones Bosques Muy Húmedos Montanos, Bosques Muy Húmedos Premontanos y Bosques Húmedos Amazónicos, entre los 100 y 3500 m de altitud. Se aplicaron las categorías y criterios de la UICN a 83 taxones. Aparentemente, 29 taxones endémicos están representados en el Sistema Nacional de Áreas Naturales Protegidas por el Estado.

Palabras claves: Melastomataceae, Miconia, Perú, endemismo, plantas endémicas.

\section{Abstract}

The Melastomataceae are represented in Peru by 43 genera and 660 species (Brako \& Zarucchi, 1993; Ulloa Ulloa et al., 2004), mostly shrubs and trees. Here we recognize 169 species and 13 infraespecific taxa as endemics, in 26 genera. Miconia is the genus with the largest number of endemic species. Endemic Melastomataceae are found mainly in Very Humid Montane, Very Humid Premontane Forests and Humid Lowland Amazonian Forests regions, between 100 and 3500 m elevation. We applied IUCN categories and criteria to 83 taxa. Apparently, 29 endemic taxa have been recorded within Peru's protected areas system.

Keywords: Melastomataceae, Miconia, Peru, endemism, endemic plants.

\section{Adelobotrys praetexta Pilg.}

Publicación: Verh. Bot. Vereins Prov. Brandenburg 47: 167. 1905.

Colección tipo: E.H.G. Ule 6368

Herbarios: B.

Nombre común: D esconocido.

Registro departamental: AM, LO, SM.

Regiones Ecológicas: $\mathrm{BMHP}, \mathrm{BHA}$; $120-600 \mathrm{~m}$.

SINANPE: Sin registro.

Herbarios peruanos: Ninguno.

Observaciones: Este bejuco es conocido del occidente de la Amazonía peruana. El ejemplar tipo fue recolectado en 1902 del Pongo de Cainarachi en el río del mismo nombre, un afluente del Huallaga.

\section{Adelobotrys ruokolainenii L. Schulman}

$$
\text { EN, Blab(iii) }
$$

Publicación: Kew Bull. 58(2): 459-461, 463, 465, f. 1. 2003.

Colección tipo: K. Ruokolainen et al. 13745

Herbarios: K, TUR; USM.

Nombre común: D esconocido.

Registro departamental: LO.

Regiones Ecológicas: BHA; 150-200 m.

SINAN PE: Sin registro.

Herbarios peruanos: AMAZ (6), USM

(holotipo citado+6).
Observaciones: Liana, conocida sólo en frutos, exclusiva de ambientes oligotróficos, en suelos no inundables. Las dos localidades conocidas están distantes aproximadamente $20 \mathrm{~km}$. Sin lugar a dudas, la cercanía a la carretera de conexión a Iquitos ha impactado a las poblaciones de esta especie, condición que fue comentada por Schulman (2003) y que empleó para aplicar la categoría de En Peligro, con la cual concordamos. La amenaza principal es la deforestación asociada a la expansión urbana.

\section{Alloneuron liron B. Walln.}

\section{CR, Blab(iii)}

Publicación: Ann. Naturhist. Mus. Wien, Ser. B, Bot. Zool. 98(Suppl.): 457-461, f. 5-6. 1996.

Colección tipo: R. Kayap 248

Herbarios: MO.

Nombre común: D esconocido.

Registro departamental: AM.

Regiones Ecológicas: $\mathrm{BHA}$; altitud desconocida.

SINAN PE: ZRSC

Herbarios peruanos: Ninguno.

Observaciones: Este arbusto se conoce del área de la Cordillera del Cóndor, en la cuenca del río Cenepa y que está incluida en la Zona Reservada Santiago-Comaina. Se espera que con el interés binacional, Perú-Ecuador, por conocer la diversidad biológica de esa parte limítrofe, pueda contribuirse a conocer mejor esta especie.

Nota del Editor: En la versión on line de este artículo han sido omitidos los mapas del Perú que ilustraban el Registro departamental. Para ubicar las abreviaturas de los departamentos vea al final del artículo. 


\section{Alloneuron majus (Markgr.) Markgr. ex J.F. Macbr.} EN, B1ab(iii)

Publicación: Trop. Woods 17: 13. 1929. Colección tipo: G. Tessmann 4625

Herbarios: B (d), NY.

Nombre común: D esconocido.

Registro departamental: AM, HU, PA.

Regiones Ecológicas: $\mathrm{BMHP}, \mathrm{BHA}$; $160-800 \mathrm{~m}$.

SINAN PE: Sin registro.

Hembarios peruanos: USM (1).

Observaciones: Arbusto, descrito de una planta recolectada en 1924 de la cuenca del Marañón. O tras poblaciones conocidas se hallan en las cuencas del Pachitea y Palcazú. Esta especie ha sido recolectada en los alrededores de la Reserva Comunal del Sira y dado el avance de la frontera agrícola en esa zona es probable que las poblaciones de esta especie estén allí muy amenazadas.

\section{Alloneuron ronliesneri B. Walln.}

\section{EN, Bla}

Publicación: Ann. Naturhist. Mus. Wien, Ser. B, Bot. Zool. 101: 595-598, f. 1-3. 1999. Colección tipo: R. Rojas et al. 454

Herbarios: MO; HUT!.

Nombre común: D esconocido.

Registro departamental: AM.

Regiones Ecológicas: BMHP; 650-800 m.

SINAN PE: Sin registro.

Herbarios peruanos: HUT (isotipo), MOLF (1).

Observaciones: Especie herbácea reconocida en 1999, que se conoce solamente de una localidad en el norte del país, en la cuenca del Imaza. Aparentemente es una especialista de hábitat en rocas calizas. Poco se conoce de la flora de este tipo de hábitat que en el país alberga varios endemismos.

\section{Axinaea glandulosa Ruiz \& Pav. Ex D. Don}

$$
\text { EN, Blab(iii) }
$$

Publicación: Fl. Peruv. 4: t. 412. 1802. Colección tipo: H. Ruiz \& J. Pavón s.n. Herbarios: $B, K$.

Nombre común: D esconocido.

Registro departamental: HU.

Regiones Ecológicas: BMHM; altitud desconocida.

SINAN PE: Sin registro.

Herbarios peruanos: Ninguno.

Observaciones: Árbol o arbusto, conocido en el Perú de unas pocas localidades en la cuenca del Huallaga. Esta especie fue descrita de una plantarecolectadaen el siglo XVIII. A parentementelasúltimas poblaciones registradas en esa cuenca provienen de los años 1920.

\section{Axinaea mertensioides Wurdack}

\section{CR, Bla}

Publicación: Phytologia 9(7): 409—410. 1964. Colección tipo: J.J. Wurdack 1467

Herbarios: MO, UC, US; USM!.

Nombre común: D esconocido.

Registro departamental: AM.

Regiones Ecológicas: BMHM; 2350$2400 \mathrm{~m}$.

SINAN PE: Sin registro.

Herbarios peruanos: USM (isotipo).
Observaciones: Arbusto descrito de una planta recolectada en 1962, de un matorral ribereño. Esta población era numerosa, con individuos dispersos en la cuenca del Ventilla, un tributario del Utcubamba; sin embargo, no se conocen poblaciones adicionales, ni colecciones. Los matorrales en la zona están sujetos a incendios intencionales y podrían considerarse como amenaza.

\section{Axinaea nitida Cogn.}

LC

Publicación: Bot. Jahrb. Syst. 42: 138. 1908.

Colección tipo: A. Weberbauer 4355

Herbarios: B; MOL!.

Nombre común: Zarcilleja.

Registro departamental: AM, CA, HU.

Regiones Ecológicas: BMHM; 2200$3100 \mathrm{~m}$.

SINAN PE: PNC

Herbarios peruanos: CPUN (3), MOL (isotipo).

Observaciones: Esta especie arbustiva se conoce de varias localidades, en el norte del país, como en las cuencas del Utcubamba y Marañón, en donde ha sido recolectada hasta 1995. Aparentemente sobrevive en ambientes intervenidos y está representada en un área protegida. Se la considera aquí de preocupación menor. Parece que hibridiza con otra endémica, A xinaea tomentosa (Wurdack, 1964: 411.)

\section{Axinaea pennellii Gleason \\ CR, Bla}

Publicación: Bull. Torrey Bot. Club 54: 28. 1927.

Colección tipo: F.W. Pennell 14003

Herbarios: NY, PH.

Nombre común: D esconocido.

Registro departamental: CU.

Regiones Ecológicas: BMHM; 2300$3000 \mathrm{~m}$.

SINAN PE: Sin registro.

Hemarios peruanos: Ninguno.

Observaciones: Árbol, conocido sólo del sur del país; reportes de Pasco son aún dudosos. Aparentemente no ha vuelto a ser recolectada desde la década de 1920. La localidad original se halla en la zona de influencia del Parque Nacional Manu, donde se asume persista esta especie.

\section{Axinaea tomentosa Cogn.}

$$
\text { EN, Bla }
$$

Publicación: Monogr. Phan. 7: 451. 1891.

Colección tipo: A. Mathews s.n.

Hembarios: B, G, K, NY.

Nombre común: Desconocido.

Registro departamental: AM, SM.

Regiones Ecológicas: BMHM; 2500$2800 \mathrm{~m}$.

SINAN PE: Sin registro.

Herbarios peruanos: Ninguno.

Observaciones: Esta especie arbustiva es conocida de unas pocas poblaciones, en el nor-oriente del país, de las cuencas del Utcubamba y Marañón. Cuenta con poblaciones de numerosos individuos que ocupan ambientes abiertos en la jalca. En esos ambientes, los incendios intencionales podrían considerarse una amenaza. 


\section{Axinaea tovanii Wurdack}

$$
\text { CR, Blab(iii) }
$$

Publicación: Phytologia 13(2): 70-71. 1966.

Colección tipo: 0 . Tovar 4753

Herbarios: US.

Nombre común: D esconocido.

Registro departamental: HV.

Regiones Ecológicas: BMHM; $2700 \mathrm{~m}$.

SINANPE: Sin registro.

Herbarios peruanos: Ninguno.

Observaciones: Árbol, conocido de la colección tipo proveniente de la cuenca del Mantaro. La localidad original está siendo afectada por la tala y los incendios intencionales asociados a la expansión agrícola. El área hospeda otras especies endémicas.

\section{Axinaea webenbaueri Cogn.}

\section{DD}

Publicación: Bot. Jahrb. Syst. 50(Beibl. 111): 32.1913.

Colección tipo: A. Weberbauer 5648

Hembarios: B, F, US.

Nombre común: D esconocido.

Registro departamental: AY, HU.

Regiones Ecológicas: BPM; 2700-3000 m.

SINANPE: Sin registro.

Hembarios peruanos: Ninguno.

Observaciones: Árbol conocido de unas pocas localidades, en la vertiente oriental, de las cuencas del Apurímac y Huallaga. No se conoce el estado de sus poblaciones.

\section{Blakea standleyana J.F. Macbr.}

\section{LC}

Publicación: Field Mus. Nat. Hist., Bot. Ser. 13(4/ 1): 516. 1941

Colección tipo: Y. Mexia 8307

Herbarios: F, US.

Nombre común: D esconocido.

Registro departamental: AM, HU, SM.

Regiones Ecológicas: $\mathrm{BMHP}, \mathrm{BHA}$; 450- $1260 \mathrm{~m}$.

SINANPE: BPAM

Herbarios peruanos: CPUN (1).

Observaciones: Esta especie arbustiva se conoce de varias localidades en el norte y centro del país. Fue recolectada inicialmente en Huánuco, en la cuenca del nío Huallaga. Hoy se conoce del Bosque de Protección Alto Mayo, en lacuencadel mismo nombreydelacuencadel Cenepa. Probablemente esté representada en la flora ecuatoriana, si bien no fue incluida por Jørgensen \& León Yánez (1999).

\section{Brachyotum angustifolium Wurdack}

\section{VU, Bla}

Publicación: Mem. New York Bot. Gard. 8(4): 401.1953.

Colección tipo: A. Mathews s.n.

Hembarios: $\mathrm{K}$.

Nombre común: D esconocido.

Registro departamental: AM, SM.

Regiones Ecológicas: PAR, BPM; 3360-

$3500 \mathrm{~m}$.

SINAN PE: PNRA

Herbarios peruanos: MOL (1), USM (1).
Observaciones: Rabusto conocido de unas pocas localidades paramunas, en el norte del país, en las cuencas del Marañón y del Abiseo. Una planta recolectada en Bolivia se atribuye a esta especie, pero no pudo confirmarse esaidentificación, por lo que se le continúa aceptando como un endemismo. 0 cupa ambientes rocosos; tal vez por ello no sea afectada por los incendios intencionales asociados a las actividades agrícolas.

\section{Brachyotum barbeyanum Cogn.}

DD

Publicación: Monogr. Phan. 7: 158. 1891.

Colección tipo: A. Mathews s.n.

Herbarios: G, NY.

Nombre común: D esconocido.

Registro departamental: AM, PA.

Regiones Ecológicas: $\mathrm{BMHM}$; altitud desconocida.

SINANPE: Sin registro.

Herbarios peruanos: USM (2).

Observaciones: Arbusto descrito de una planta recolectada en 1862. Una población adicional fue recolectada 100 años después, en la cuenca del Utcubamba, mientras que una disyunta se localiza en la cuenca del Pozuzo. No se conoce el estado de sus poblaciones.

\section{Brachyotum cogniauxii Wurdack}

\section{VU, Bla}

Publicación: Mem. New York Bot. Gard. 8(4): 392. 1953.

Colección tipo: F.W. Pennell 15660

Hembarios: PH; USM!

Nombre común: D esconocido.

Registro departamental: AM, LL.

Regiones Ecológicas: $\mathrm{PAR}, \mathrm{BMHM}$; 2400- $3500 \mathrm{~m}$.

SINANPE: Sin registro.

Herbarios peruanos: CPUN (1), USM (isotipo).

Observaciones: Arbusto, conocido de poblaciones dispersas en el norte del país, principalmente en la cuenca del Marañón, donde ocupa pajonales dejalca, sobre laderas pedregosas o en sitios anegados dominados por Sphagnum. Probablemente, los incendios intencionales y las actividades mineras podrían afectar sus poblaciones.

\section{Brachyotum comatum (Triana) Wurdack}

\section{VU, B1a}

Publicación: Phytologia 11(6): 379. 1965. Colección tipo: A. Mathews 3211

Herbarios: K.

Nombre común: Castano.

Registro departamental: AM, CA. Regiones Ecológicas: $\mathrm{BPM}, \mathrm{BMHM}$; 2400- $3200 \mathrm{~m}$.

SINAN PE: Sin registro.

Hemarios penuanos: CPUN (2), HAO (1).

Observaciones: Arbusto conocido de ambas vertientes, en el norte del país. En el flanco occidental, ha sido recolectada en fragmentos de bosque del Bosque Protector Ucshahuillcay del Bosque El Pargo. Esta especie se conoce también de Cerros Calla Calla, localidad que alberga varios endemismos, pero que está siendo deforestada. 


\section{Brachyotum cutervoanum Wurdack}

$$
\text { EN, B1ab(iii) }
$$

Publicación: Phytologia 14(5): 257-258. 1967.

Colección tipo: A. Sagástegui A. 5384

Henbarios: US; HUT!.

Nombre común: D esconocido.

Registro departamental: CA.

Regiones Ecológicas: BMHM; 2260$2420 \mathrm{~m}$.

SINAN PE: PNC

Herbarios penuanos: CPUN (1), HAO (1),

HUT (isotipo)

Observaciones: Arbusto de flores moradas, conocida sólo de la vertiente oriental, en el norte del país. Todos los ejemplares provienen de la Provincia de Cutervo, de altitudes que en el pasado estaban cubiertas de bosques más extensos. Si bien hay recolectas hasta 1994, podría estar amenazada por los incendios asociados a la actividad agrícola. Por su distribución limitada se la considera amenazada.

\section{Brachyotum figueroae J.F. Macbr.}

\section{LC}

Publicación: Publ. Field Columbian Mus., Bot. Ser. 4: 173. 1929.

Colección tipo: J.F. Macbride \& W. Featherstone 2504

Hembarios: F, NY.

Nombre común: Cotchkis blanco.

Registro departamental: AN, CA, LA, LL. Regiones Ecológicas: PSH, PAR; 2850$4040 \mathrm{~m}$.

SINAN PE: PNH

Hemarios peruanos: CPUN (3), HAO (1).

Observaciones: Arbusto de flores rosadas a blanco-verdosas, conocida de varias localidades, en el norte del país, donde ocupa pajonales y matorrales intervenidos. Su rango altitudinal es amplio, algo mayor a los $1000 \mathrm{~m}$. Por la plasticidad en su hábitat y área de presencia se la considera de preocupación menor.

\section{Brachyotum huancavelicae Wurdack}

\section{DD}

Publicación: Mem. New York Bot. Gard. 8(4): 381. 1953.

Colección tipo: H.E. Stork \& O.B. Horton 10295

Hembarios: F, G, UC.

Nombre común: D esconocido.

Registro departamental: HU, HV, JU.

Regiones Ecológicas: MA; 3000-3300 $\mathrm{m}$.

SINANPE: USM (1)

Herbarios peruanos: Ninguno.

Observaciones: Arbusto conocido de unas pocas localidades, en el centro del país, en las cuencas del Mantaro y Comas. Fue descrita de una planta recolectada en 1939. Incendios intencionales podrían afectar los matorrales que habita; aunque no se conoce las condiciones de sus poblaciones.

\section{Brachyotum intermedium Wurdack}

Publicación: Mem. New York Bot. Gard. 8(4): 367. 1953.

Colección tipo: A. Mathews 3210 p.p.

Herbarios: $\mathrm{K}$.

Nombre común: D esconocido.

Registro departamental: AM.

Regiones Ecológicas: Sin datos; altitud desconocida.

SINANPE: Sin registro.

Herbarios peruanos: Ninguno.

Observaciones: Este taxón arbustivo fue considerado por Brako \& Zarucchi (1993) como un endemismo; sin embargo, no ha sido posible evaluarlo, ni asignarle una categoría.

\section{Brachyotum longisepalum Wurdack}

\section{VU, Bla}

Publicación: Phytologia 11(6): 381. 1965. Colección tipo: A. López M. \& A. Sagástegui A. 3338

Herbarios: US; HUT!

Nombre común: D esconocido.

Registro departamental: AN, CA, LL. Regiones Ecológicas: PSH, PAR; 3500$4200 \mathrm{~m}$.

SINANPE: PNH

Herbarios penuanos: HUT (isotipo), USM (3).

Observaciones: Esta especie arbustiva no fue señalada como un endemismo por Brako \& Zarucchi (1993), si bien es sólo conocida de unas pocas localidades en el norte del país, de las cuenca del Marañón, Crisneja y Santa, donde ocupa matorrales dispersos en áreas ecotonales entre pajonal y bosque. Localmente escasa, por lo que incendios intencionales afectan sus poblaciones.

\section{Brachyotum lutescens (Ruiz \& Pav.) Triana}

\section{CR, Bla}

Publicación: Trans. Linn. Soc. London 28(1): 48. [1872]. 1871.

Colección tipo: H. Ruiz \& J. Pavón s.n. Herbarios: MA.

Nombre común: D esconocido.

Registro departamental: HU.

Regiones Ecológicas: MA, BMHM; altitud desconocida.

SINANPE: Sin registro.

Herbarios peruanos: Ninguno.

Observaciones: Esta especie fue mencionada por Macbride (1941) con ejemplares procedentes de varias localidades de Huánuco (Chaglla, Mito y Muña), todas en la provincia de Ambo. Brako \& Zarucchi (1993) la consideraron como presente en Loreto, pero ese registro es un error. No ha vuelto a ser recolectada desde fines del siglo XVIII.

\section{Brachyotum maximowicziiCogn. longifolium Wurdack}

Publicación: Mem. New York Bot. Gard. 8(4): 369. 1953.

Colección tipo: F.W. Pennell 15857

Herbarios: PH; USM!.

Nombre común: D esconocido.

Registro departamental: AM.

Regiones Ecológicas: BMHM; 3000$3200 \mathrm{~m}$.

SINAN PE: Sin registro.

Herbarios peruanos: USM (isotipo). 
Observaciones: Arbusto reconocido del norte del país, donde fue recolectado de suelos arenosos. No ha sido posible evaluarlo, ni asignarle una categoría.

\section{Brachyotum maximowicziiCogn. maximowiczii}

Publicación:

Colección tipo: Fielding 1265

Herbarios: BR, K, L.

Nombre común: D esconocido.

Registro departamental: AM.

Regiones Ecológicas: BMHM; 2300$3000 \mathrm{~m}$.

SINAN PE: Sin registro.

Herbarios penuanos: HUT (1).

Observaciones: Este taxón arbustivo fue considerado por Brako \& Zarucchi (1993) como un endemismo; sin embargo, no ha sido posible evaluarlo, ni asignarle una categoría.

\section{Brachyotum multinervium Wurdack}

$$
\text { CR, B1ab(iii) }
$$

Publicación: Phytologia 11(6): 379-380. 1965.

Colección tipo: J.J. Wurdack 1304

Herbarios: US.

Nombre común: D esconocido.

Registro departamental: AM.

Regiones Ecológicas: BMHM; 3100$3250 \mathrm{~m}$.

SINANPE: Sin registro.

Herbarios peruanos: Ninguno.

Observaciones: Arbusto, conocido solamente de una localidad en Cerros Calla Calla, la cual está siendo deforestada. La población más recientefue recolectada en 1977. Su área de presencia es muy reducida y no está representada en alguna de las áreas protegidas.

\section{Brachyotum multituberculum Wurdack}

Publicación: Mem. New York Bot. Gard. 8(4): 394-395. 1953.

Colección tipo: L. Williams 7587

Herbarios: F.

Nombre común: D esconocido.

Registro departamental: AM.

Regiones Ecológicas: PAR; 2700-3300 m.

SINAN PE: Sin registro.

Herbarios peruanos: Ninguno.

Observaciones: Este taxón arbustivo fue considerado por Brako \& Zarucchi (1993) como un endemismo; sin embargo, no ha sido posible evaluarlo, ni asignarle una categoría.

\section{Brachyotum parvifolium Cogn.}

Publicación: Bot. Jahrb. Syst. 42: 132. 1908.

Colección tipo: A. Weberbauer 4406

Herbarios: B.

Nombre común: D esconocido.

Registro departamental: AM, LA.

Regiones Ecológicas: PAR, BMHM; 2535- $3100 \mathrm{~m}$.

SINAN PE: Sin registro.

Herbarios peruanos: Ninguno.
Observaciones: Este taxón arbustivo fue considerado por Brako \& Zarucchi (1993) como un endemismo; sin embargo, no ha sido posible evaluarlo, ni asignarle una categoría.

\section{Brachyotum radula Triana}

\section{VU, B lab(iii)}

Publicación: Trans. Linn. Soc. London 28(1): 48, t. 3. [1872]. 1871.

Colección tipo: A. Mathews 3210

Herbarios: $\mathrm{K}$.

Nombre común: Zarcilleja (Mostacero et al. 1148).

Registro departamental: AM, CA.

Regiones Ecológicas: MA, PAR, BMHM; 2650- $3400 \mathrm{~m}$.

SINAN PE: Sin registro.

Herbarios penuanos: CPUN (3), HUT (4), MOL (1).

Observaciones: Arbusto de flores rosadas a lilas, conocida de ambas vertientes andinas, en el norte del país, en numerosas localidades. Probablemente las poblaciones más amenazadas correspondan a las ubicadas en los alrededores de Taulis en Cajamarca.

\section{Brachyotum rosmaninifolium (Ruiz \& Pav.) Triana}

Publicación: Trans. Linn. Soc. London 28(1): 49. [1872]. 1871.

Colección tipo: H. Ruiz \& J. Pavón s.n.

Herbarios: $F$.

Nombre común: Cachiquis.

Registro departamental: AN, HU, JU.

Regiones Ecológicas: PSH, AA; 3900$4400 \mathrm{~m}$.

SINAN PE: PNH

Hembarios penuanos: CPUN (1), MOL (1).

Observaciones: Este taxón fue considerado por Brako \& Zarucchi (1993) como un endemismo; sin embargo, no ha sido posible evaluarlo, ni asignarle una categoría.

\section{Brachyotum tyrianthinum J.F. Macbr.}

$$
\text { VU, Bla }
$$

Publicación: Publ. Field Columbian Mus., Bot. Ser. 4: 174. 1929.

Colección tipo: J.F. Macbride \& W. Featherstone 1438

Hembarios: F, US.

Nombre común: Cachis.

Registro departamental: CA, HU.

Regiones Ecológicas: MA; 2800-3200 $\mathrm{m}$.

SINAN PE: Sin registro.

Hembarios penuanos: CPUN (2), HUT (2).

Observaciones: Arbusto, conocio de laderas en el lado oriental de los Andes de Cajamarca y Huánuco, con ambientes transicionales húmedos amarcadamente estacionales. Las colecciones más recientes provienen de Celendín, en la cuenca del Marañón. La distancia más extrema en línea recta entre localidades supera los $450 \mathrm{~km}$. Habita ambientes en donde las actividades agropastoriles son causa de cambio en el paisaje. 
32. Brachyotum virescens (Cogn.) Wurdack

$$
\text { EN, B1ab(iii) }
$$

Publicación: Phytologia 64(4): 296. 1988. Colección tipo: A. Weberbauer 2475

Herbarios: B.

Nombre común: D esconocido.

Registro departamental: JU.

Regiones Ecológicas: $\mathrm{BPM}, \mathrm{BMHM}$; 2750- $3100 \mathrm{~m}$.

SINAN PE: Sin registro.

Herbarios peruanos: Ninguno.

Observaciones: Arbusto conocido solamente de dos localidades muy cercanas en la cuenca del Tulumayo, en la vertiente oriental de Junín. Brako \& Zarucchi (1993) no indicaron su carácter de endemismo. La colección tipo fue realizada a inicios del siglo XX, pero recién a fines de la década de 1980 se reconfirmó esta especie y su estatus taxonómico (Wurdack, 1988). Probablemente los incendios intencionales producto de la expansión agrícola podrían ser amenaza a las poblaciones de esta especie.

\section{Brachyotum weberbaueni Cogn.}

\section{DD}

Publicación: Bot. Jahrb. Syst. 42: 133. 1908. Colección tipo: A. Weberbauer 4405

Herbarios: BR, G; MOL!.

Nombre común: D esconocido.

Registro departamental: AM.

Regiones Ecológicas: BMHM; 2400$3100 \mathrm{~m}$.

SINAN PE: Sin registro.

Herbarios penuanos: MOL (isotipo).

Observaciones: Arbusto conocido del área entre la cuenca media del Marañón y la alta del Utcubamba. Esta especie fue inicialmente recolectada en 1904. No se conoce el estado se sus poblaciones.

\section{Centradeniastrum roseum Cogn.}

EN, B 1ab(iii)

Publicación: Bot. Jahrb. Syst. 42: 131132. 1908.

Colección tipo: A. Weberbauer 4086

Herbarios: B, BR.

Nombre común: Desconocido.

Registro departamental: CA.

Regiones Ecológicas: MA; 2700- $2900 \mathrm{~m}$.

SINAN PE: Sin registro.

Herbarios peruanos: CPUN (1)?, HUT (1)?

Observaciones: Esta especie arbustiva se conoce de la cuenca alta del río Chancay, sobre la vertiente occidental. Los ambientes de donde se conoce esta especie están fragmentados y expuestos a incendios intencionales y pastoreo intensivo. El ejemplar tipo no fue ubicado en las colecciones peruanas (Almeda, 1997).

35. Centronia peruviana J.F. Macbr.

EN, B1a

Publicación: Field Mus. Nat. Hist., Bot. Ser. 13(4/ 1): 327-328. 1941.

Colección tipo: H.E. Stork \& O.B. Horton 9928

Herbarios: US.

Nombre común: D esconocido.

Registro departamental: HU.

Regiones Ecológicas: BMHM; $2850 \mathrm{~m}$.

SINANPE: Sin registro.

Herbarios peruanos: Ninguno.
Observaciones: Arbusto conocido solamente del centro oriente del país, de la cuenca del Huallaga. Fue recolectada originalmente en Carpish, en los años 1930, esta zona alberga varios endemismos, pero está severamente afectada por la deforestación, por lo que debería ser de interés su conservación.

\section{Clidemia foliosa Gleason}

Publicación: Bull. Torrey Bot. Club 58(2): 84-85. 1931.

Colección tipo: L. Williams 933

Herbarios: $F$, NY.

Nombre común: D esconocido.

Registro departamental: LO.

Regiones Ecológicas: BHA; altitud desconocida.

SINAN PE: Sin registro.

Herbarios peruanos: Ninguno.

Observaciones: Arbusto, conocido solamente de una localidad, en la cuencadel Nanay. No hasido posible evaluarlo, ni asignarleunacategoná.

\section{Clidemia heteronenvis (Naudin) Wurdack}

Publicación: Phytologia 21(2): 126. 1971. Colección tipo: C. Gay s.n.

Hembarios: P.

Nombre común: D esconocido.

Registro departamental: CU.

Regiones Ecológicas: BMHP; 700-800 m.

SINAN PE: Sin registro.

Herbarios peruanos: Ninguno.

Observaciones: Arbusto conocido de la cuenca del Cosñipata, un tributario del Madre de Dios. Este taxón fue considerado por Brako \& Zarucchi (1993) como un endemismo; sin embargo, no ha sido posible evaluarlo, ni asignarle una categoría.

\section{Clidemia longifolia Gleason}

Publicación: Bull. Torrey Bot. Club 58: 254. 1931.

Colección tipo: G. Klug 62

Herbarios: NY, US.

Nombre común: Desconocido.

Registro departamental: HU, LO.

Regiones Ecológicas: BHA; $100 \mathrm{~m}$.

SINAN PE: Sin registro.

Herbarios peruanos: Ninguno.

Observaciones: Este taxón fue considerado por Brako \& Zarucchi (1993) como un endemismo; sin embargo, no ha sido posible evaluarlo, ni asignarle una categoría.

\section{Clidemia ulei Pilg.}

Publicación: Verh. Bot. Vereins Prov. Brandenburg 47: 180. 1905.

Colección tipo: E.H.G. Ule 6235

Henbarios: $B$.

Nombre común: Mullaca.

Registro departamental: LO.

Regiones Ecológicas: BHA; altitud desconocida.

SINANPE: Sin registro.

Herbarios peruanos: Ninguno. 
Observaciones: Este taxón arbustivo fue considerado por Brako \& Zarucchi (1993) como un endemismo; sin embargo, no ha sido posible evaluarlo, ni asignarle una categoría.

\section{Ernestia qudriseta 0. Berg ex Triana}

Publicación: Trans. Linn. Soc. London 28(1): 35-36. [1871]. 1872.

Colección tipo: R. Spruce 4584

Herbarios: $C, P$.

Nombre común: D esconocido.

Registro departamental: LO, SM.

Regiones Ecológicas: Sin datos; altitud desconocida.

SINANPE: Sin registro.

Herbarios peruanos: Ninguno.

Observaciones: Este taxón fue considerado por Brako \& Zarucchi (1993) como un endemismo; sin embargo, no ha sido posible evaluarlo, ni asignarle una categoría.

\section{Graffennieda cinna J.F. Macbr.}

Publicación: Field Mus. Nat. Hist., Bot. Ser. 13(4/ 1): 321. 1941.

Colección tipo: G. Klug 3313

Herbarios: $F$.

Nombre común: D esconocido.

Registro departamental: SM.

Regiones Ecológicas: Sin datos; altitud desconocida.

SINANPE: Sin registro.

Herbarios peruanos: Ninguno.

Observaciones: Este taxón fue considerado por Brako \& Zarucchi (1993) como un endemismo; sin embargo, no ha sido posible evaluarlo, ni asignarle una categoría.

\section{Graffenrieda foliosa Cogn.}

Publicación: Bot. Jahrb. Syst. 42: 137. 1908.

Colección tipo: A. Weberbauer 3544

Herbarios: B; MOL!.

Nombre común: D esconocido.

Registro departamental: HU.

Regiones Ecológicas: Sin datos; $2000 \mathrm{~m}$.

SINAN PE: Sin registro.

Hemarios peruanos: MOL (isotipo).

Observaciones: Este taxón fue considerado por Brako \& Zarucchi (1993) como un endemismo; sin embargo, no ha sido posible evaluarlo, ni asignarle una categoría.

\section{Graffennieda robusta (Cogn.) L.O. Williams}

Publicación: Fieldiana, Bot. 29(10): 564. 1963.

Colección tipo: A. Weberbauer 3572

Herbarios: Sin datos.

Nombre común: D esconocido.

Registro departamental: HU.

Regiones Ecológicas: Sin datos; altitud desconocida.

SINANPE: Sin registro.

Herbarios peruanos: Ninguno.
Observaciones: Este taxón fue considerado por Brako \& Zarucchi (1993) como un endemismo; sin embargo, no ha sido posible evaluarlo, ni asignarle una categoría.

\section{Graffenrieda trichanthera Gleason}

Publicación: Bull. Torrey Bot. Club 63: 533. 1936.

Colección tipo: G. Klug 3298

Hembarios: NY.

Nombre común: D esconocido.

Registro departamental: SM.

Regiones Ecológicas: BMHP; 1100 $1200 \mathrm{~m}$.

SINAN PE: Sin registro.

Herbarios peruanos: Ninguno.

Observaciones: Este taxón fue considerado por Brako \& Zarucchi (1993) como un endemismo; sin embargo, no ha sido posible evaluarlo, ni asignarle una categoría.

\section{Graffennieda tristis (Triana) L.0. Williams}

Publicación: Fieldiana, Bot. 29(10): 564. 1963. Colección tipo: R. Spruce 4823

Herbarios: Sin datos.

Nombre común: D esconocido.

Registro departamental: LO, SM.

Regiones Ecológicas: Sin datos; altitud desconocida

SINANPE: Sin registro.

Hemarios peruanos: Ninguno.

Observaciones: Estetaxón fue considerado por Brako \& Zarucchi (1993) como un endemismo; sin embargo, no ha sido posible evaluarlo, ni asignarle una categoría.

\section{Hubenia cogniauxii Baumgratz}

Publicación: Novon 9: 143. 1999.

Colección tipo: B. Stein \& C. Todzia 2216

Herbarios: CAS, MO, RB.

Nombre común: D esconocido.

Registro departamental: AM.

Regiones Ecológicas: BMHM; 2450$3350 \mathrm{~m}$.

SINAN PE: Sin registro.

Herbarios peruanos: Ninguno.

Observaciones: Este taxón arbustivo fue descrito posterior a Brako \& Zarucchi (1993); no ha sido posible evaluarlo, ni asignarle una categoría.

\section{H uberia staminodia Baumgratz}

Publicación: Novon 9: 139. 1999.

Colección tipo: P.C. Hutchison \& J.K. Wright 3995

Herbarios: F, K, NY, US; USM.

Nombre común: D esconocido.

Registro departamental: AM.

Regiones Ecológicas: BMHM; 1520 m.

SINAN PE: Sin registro.

Herbarios peruanos: USM (isotipo citado). 
Observaciones: Este taxón fue descrito posterior a Brako \& Zarucchi (1993); no ha sido posible evaluarlo, ni asignarle una categoná.

\section{Huberia webemaueniana Baumgratz}

Publicación: Novon 9: 140. 1999.

Colección tipo: A. Weberbauer 7145

Herbarios: F, GH, US.

Nombre común: D esconocido.

Registro departamental: AM.

Regiones Ecológicas: BMHM; $1700 \mathrm{~m}$.

SINANPE: Sin registro.

Herbarios peruanos: Ninguno.

Observaciones: Este taxón fue descrito posterior a Brako \& Zarucchi (1993); no ha sido posible evaluarlo, ni asignarle una categoría.

\section{Icaria fictilis J.F. Macbr.}

Publicación: Publ. Field Columbian Mus., Bot. Ser. 4: 191. 1929.

Colección tipo: J.F. Macbride 4431

Hembarios: $F$.

Nombre común: D esconocido.

Registro departamental: HU.

Regiones Ecológicas: Sin datos; altitud desconocida.

SINAN PE: Sin registro.

Hemarios peruanos: Ninguno.

Observaciones: Este taxón fue considerado por Brako \& Zarucchi (1993) como un endemismo; sin embargo, no ha sido posible evaluarlo, ni asignarle una categoría.

\section{Leandra peltata Wurdack}

Publicación: Phytologia 11(6): 384-385. 1965.

Colección tipo: J.J. Wurdack 2474

Herbarios: NY, US; USM.

Nombre común: D esconocido.

Registro departamental: AM.

Regiones Ecológicas: BHA; 300-350 m.

SINANPE: ZRSC

Herbarios peruanos: USM (isotipo citado).

Observaciones: Arbusto conocido delacuencadel Santiago, debosques no inundables. No ha sido posible evaluarlo, ni asignarle una categoná.

\section{Leandra raimondiana Markgr.}

Publicación: Notizbl. Bot. Gart. BerlinDahlem 13: 464. 1937.

Colección tipo: A. Raimondi 10982

Herbarios: USM.

Nombre común: D esconocido.

Registro departamental: PU.

Regiones Ecológicas: Sin datos; altitud desconocida.

SINAN PE: Sin registro.

Herbarios peruanos: USM (holotipo citado).

Observaciones: Este taxón fue considerado por Brako \& Zarucchi (1993) como un endemismo; sin embargo, no ha sido posible evaluarlo, ni asignarle una categoría.
52. Leandra rotundifolia J.F. Macbr.

Publicación: Field Mus. Nat. Hist., Bot. Ser. 13(4/ 1): 339. 1941.

Colección tipo: J.M. Schunke 176

Herbarios: $F$.

Nombre común: D esconocido.

Registro departamental: LO.

Regiones Ecológicas: Sin datos; altitud desconocida.

SINANPE: Sin registro.

Hemarios peruanos: Ninguno.

Observaciones: Este taxón fue considerado por Brako \& Zarucchi (1993) como un endemismo; sin embargo, no ha sido posible evaluarlo, ni asignarle una categoría.

\section{Meriania amischophylla Wurdack}

\section{CR, Blab(iii)}

Publicación: Phytologia 48(3): 238- 239. 1981.

Colección tipo: J. Schunke V. 9842

Herbarios: MO, US.

Nombre común: D esconocido.

Registro departamental: UC.

Regiones Ecológicas: BMHM; 1500$1600 \mathrm{~m}$

SINAN PE: Sin registro.

Herbarios peruanos: Ninguno.

Observaciones: Arbusto descrito de dos ejemplares recolectados en la localidad tipo, que está ubicada en el límite sur del Parque Nacional Cordillera Azul. Esta especie no fue reconocida como endémica por Brako \& Zarucchi (1993), atribuyéndose la localidad tipo a Huánuco. Probablemente, otras poblaciones estén presentes en el parque vecino y tal vez en los remanentes de bosque en Huánuco, aunque en esa parte del país la expansión agrícola podría ser de preocupación para la conservación de estas.

\section{Meniania cuzcoana Wurdack}

Publicación: Phytologia 13(2): 71- 72. 1966. Colección tipo: C. Vargas C. 5107

Hemarios: US; CUZ.

Nombre común: D esconocido.

Registro departamental: $\mathrm{CU}$.

Regiones Ecológicas: BMHM; 2000 m.

SINANPE: Sin registro.

Herbarios peruanos: CUZ (isotipo citado).

Observaciones: Arbusto conocido de una localidad en la cuenca del Alto Madre de Dios, muy cerca del límite del Parque Nacional Manu. No ha sido posible evaluarlo, ni asignarle una categoría.

\section{Meriania prunifolia D. D on}

Publicación: Mem. Wern. Nat. Hist. Soc. 4: 323. 1823.

Colección tipo: H. Ruiz \& J. Pavón s.n.

Herbarios: Sin datos.

Nombre común: D esconocido.

Registro departamental: SM.

Regiones Ecológicas: Sin datos; altitud desconocida.

SINAN PE: Sin registro.

Herbarios peruanos: Ninguno. 
Observaciones: Este taxón fue considerado por Brako \& Zarucchi (1993) como un endemismo; sin embargo, no ha sido posible evaluarlo, ni asignarle una categoría.

\section{Meniania rugosa Markgr.}

Publicación: Notizbl. Bot. Gart. BerlinDahlem 13: 460. 1937.

Colección tipo: A. Raimondi 1866

Herbarios: B; USM

Nombre común: D esconocido.

Registro departamental: AM.

Regiones Ecológicas: BMHM; altitud desconocida.

SINANPE: Sin registro,

Herbarios peruanos: USM (isotipo citado+2).

Observaciones: Este taxón fue considerado por Brako \& Zarucchi (1993) como un endemismo; sin embargo, no ha sido posible evaluarlo, ni asignarle una categoría.

\section{Meriania tetraquetra Triana}

\section{DD}

Publicación: Trans. Linn. Soc. London 28(1): 66. [1871]. 1872.

Colección tipo: A. Mathews s.n.

Herbarios: G.

Nombre común: D esconocido.

Registro departamental: AM, LL.

Regiones Ecológicas: BMHM; 2000$2300 \mathrm{~m}$.

SINAN PE: Sin registro.

Herbarios peruanos: Ninguno.

Observaciones: Arbusto conocido deladescripción original (Wurdack, 1964) y de un ejemplar adicional, recolectado en 1914, de la cuenca del Mixiollo. Se desconoce la situación de sus poblaciones,

\section{Meniania vargasii Wurdack}

Publicación: Phytologia 13(2): 72- 73. 1966. Colección tipo: C. Vargas C. 13240

Herbarios: US; CUZ.

Nombre común: D esconocido.

Registro departamental: CU.

Regiones Ecológicas: BMHM; $1800 \mathrm{~m}$.

SINAN PE: Sin registro.

Herbarios penuanos: CUZ (isotipo citado).

Observaciones: Arbusto considerado como un endemismo; sin embargo, no ha sido posible evaluarlo ni asignarle una categoría.

\section{Meniania vilcabambensis Wurdack}

Publicación: Phytologia 21(6): 353-354. 1971.

Colección tipo: T.R. Dudley 10595

Herbarios: NA, US.

Nombre común: D esconocido.

Registro departamental: CU.

Regiones Ecológicas: BMHM; $1730 \mathrm{~m}$.

SINAN PE: Sin registro.

Herbarios peruanos: Ninguno.
Observaciones: Árbol conocido de la Cordillera de Vilcabamba, al sur del Parque Nacional O tishi. No ha vuelto a ser recolectado desde 1968. No ha sido posible evaluarlo, ni asignarle una categoría.

\section{Meriania weberbaueri J.F. Macbr.}

Publicación: Publ. Field Columbian Mus., Bot. Ser. 4: 176. 1929.

Colección tipo: A. Weberbauer 6659

Herbarios: F; MOL!

Nombre común: D esconocido.

Registro departamental: HU, JU.

Regiones Ecológicas: Sin datos; altitud desconocida.

SINANPE: Sin registro.

Hemarios peruanos: MOL (isotipo).

Observaciones: Estetaxón fue considerado por Brako \& Zarucchi (1993) como un endemismo; sin embargo, no ha sido posible evaluarlo, ni asignarle una categoría.

\section{Miconia adinantha Wurdack}

$$
\text { VU, Blab(iii) }
$$

Publicación: Phytologia 23(5): 487-488. 1972.

Colección tipo: T.R. Dudley 10384

Herbarios: NA, US.

Nombre común: Juanjil, terri.

Registro departamental: CA, CU, PA. Regiones Ecológicas: BMHM; 1700$2500 \mathrm{~m}$.

SINANPE: PNC

Herbarios penuanos: AMAZ (1), CPUN (1), HAO (1).

Observaciones: Esta especie arbórea se conoce de ambas vertientes andinas ,en el norte del país y en la vertiente oriental en el centro del país. El ejemplar tipo fue recolectado en una localidad en la cuenca del Apurímac, al sur del Parque Nacional Otishi. Sus poblaciones podrían estar afectadas por deforestación.

\section{Miconia aligera Wurdack}

$$
\text { EN, Bla }
$$

Publicación: Phytologia 23(5): 486-487. 1972.

Colección tipo: T.R. Dudley 11261

Herbarios: NA, US.

Nombre común: D esconocido.

Registro departamental: CU.

Regiones Ecológicas: BMHM; 2080 m.

SINANPE: Sin registro.

Herbarios peruanos: Ninguno.

Observaciones: Árbol conocido de la Cordillera de Vilcabamba, al sur del área del Parque Nacional Otishi. Aparentemente no ha vuelto a ser recolectada desde 1968. Sus poblaciones podrían estar afectadas por deforestación. 


\section{Miconia alpina Cogn.}

Publicación: Bot. Jahrb. Syst. 42: 146. 1908.

Colección tipo: A. Weberbauer 4953

Herbarios: B.

Nombre común: D esconocido.

Registro departamental: AN, AP, CU, HU. Regiones Ecológicas: PSH; 3700-4200 m.

SINANPE: PNH

Herbarios penuanos: USM?

Observaciones: Arbusto, conocido de bosques andinos naturalmente fragmentados en el centro y sur del país. La mayoría de los ejemplares de herbario recientes proviene del Parque Nacional Huascarán. Por su rango de distribución conocida, podría esperarse su presencia en otras áreas protegidas como Ampay y Machu Picchu. Los ambientes donde crece esta especie están sujetos a tala e incendios intencionales.

\section{Miconia aprica Gleason}

\section{EN, Blab(iii)}

Publicación: Bull. Torrey Bot. Club 58: 244. 1931.

Colección tipo: E.P. Killip \& A.C. Smith 24246

Herbarios: NY, US.

Nombre común: D esconocido.

Registro departamental: AY, JU.

Regiones Ecológicas: BMHM; 2000$2700 \mathrm{~m}$.

SINAN PE: Sin registro.

Herbarios peruanos: Ninguno.

Observaciones: Arbusto, conocido aparentemente de tres localidades en el centro del país. La localidad tipo, en la cuenca del Tulumayo, recibe alta deforestación por la ampliación de la frontera agrícola; sin embargo, varios fragmentos grandes de bosque existen en esa cuenca, y es probable que ahí persistan poblaciones de esta especie (C. Reynel, com. pers.). En la cuenca del A purímac, también fue registrado, pero, al parecer, esa población no han vuelto a ser ubicada desde la década de 1920

\section{Miconia atrofusca Cogn.}

Publicación: Bot. Jahrb. Syst. 42: 142. 1908.

Colección tipo: A. Weberbauer 3726

Herbarios: B; MOL!

Nombre común: D esconocido.

Registro departamental: HU, PA.

Regiones Ecológicas: Sin datos; altitud desconocida.

SINANPE: Sin registro.

Herbarios peruanos: MOL (isotipo).

Observaciones: Arbusto que se conoce solamente de la cuenca del Huallaga. No ha sido posible evaluarlo, ni asignarle una categoría.

\section{Miconia ayacuchensis Wurdack}

CR, Blab(iii)

Publicación: Phytologia 23(5): 497-498. 1972.

Colección tipo: T.R. Dudley 11992

Herbarios: US

Nombre común: Desconocido.

Registro departamental: AY.

Regiones Ecológicas: BPM; 3400-3600 m.

SINAN PE: Sin registro.

Herbarios peruanos: Ninguno.

Observaciones: Arbusto, conocido solamente de una localidad en la cuenca del A purímac, en una cordillera frente a la de Vilcabamba. La población conocida habitaba matorrales ecotonales con el límite superior del bosque montano. D eforestación eincendios intencionales podrían considerarse amenazas.

\section{Miconia brachyanthera Triana}

Publicación: Trans. Linn. Soc. London 28(1): 129. [1871]. 1872.

Colección tipo: A. Mathews 1726

Herbarios: $\mathrm{K}$.

Nombre común: D esconocido.

Registro departamental: AM, HU, PA.

Regiones Ecológicas: BMHM; 2200$2300 \mathrm{~m}$.

SINANPE: Sin registro.

Herbarios peruanos: Ninguno.

Observaciones: Este taxón arbustivo fue considerado por Brako \& Zarucchi (1993) como un endemismo; sin embargo, no ha sido posible evaluarlo, ni asignarle una categoría.

\section{Miconia brevistilys Cogn.}

Publicación: Bot. Jahrb. Syst. 42: 144. 1908.

Colección tipo: A. Weberbauer 3553

Herbarios: B; MOL!.

Nombre común: D esconocido.

Registro departamental: HU.

Regiones Ecológicas: Sin datos; altitud desconocida.

SINANPE: Sin registro.

Hemanios penuanos: MOL (isotipo).

Observaciones: Este taxón fue considerado por Brako \& Zarucchi (1993) como un endemismo; sin embargo, no ha sido posible evaluarlo, ni asignarle una categoría.

\section{Miconia cerulea Pav. ex Naudin subsp. vilcabambae Wurdack}

Publicación: Phytologia 23(5): 491-492. 1972.

Colección tipo: T.R. Dudley 10421

Herbarios: NA, US.

Nombre común: D esconocido.

Registro departamental: CU.

Regiones Ecológicas: BMHM; 1460$1730 \mathrm{~m}$.

SINAN PE: Sin registro

Herbarios peruanos: Ninguno. 
Observaciones: Arbusto dioico, conocido solamente de la Cordillera de Vilcabamba de plantas masculinas. Aparentemente no ha vuelto a ser recolectado desde 1968 . No ha sido posible evaluarlo, ni asignarle una categoría.

\section{Miconia carpishana Wurdack}

$$
\text { CR, Blab(iii) }
$$

Publicación: Phytologia 13(2): 76- 77. 1966. Colección tipo: B. Maguire \& C.E. Maguire 44436

Herbarios: NY, US.

Nombre común: D esconocido.

Registro departamental: HU.

Regiones Ecológicas: BMHM; $2850 \mathrm{~m}$.

SINANPE: Sin registro.

Herbarios peruanos: Ninguno.

Observaciones: Árbol conocido delacuencadel Huallaga. Estaespecie fue descrita de una planta recolectada en Carpish en 1959, una localidad con varios endemismos, pero afectada por la deforestación.

\section{Miconia cauingia J.F. Macbr.}

Publicación: Field Mus. Nat. Hist., Bot. Ser. 13(4/ 1): 394. 1941.

Colección tipo: H.E. Stork \& O.B. Horton 9992

Herbarios: F.

Nombre común: D esconocido.

Registro departamental: CA, LL.

Regiones Ecológicas: Sin datos; altitud desconocida.

SINANPE: Sin registro.

Hembarios peruanos: Ninguno.

Observaciones: Este taxón fue considerado por Brako \& Zarucchi (1993) como un endemismo; sin embargo, no ha sido posible evaluarlo, ni asignarle una categoría.

\section{MiconiachoriophyllaWurdack brevifoliaWurdack}

\section{DD}

Publicación: Phytologia 23(5): 500-501. 1972.

Colección tipo: T.R. Dudley 13520

Herbarios: NA.

Nombre común: D esconocido.

Registro departamental: HU.

Regiones Ecológicas: BMHM; $1680 \mathrm{~m}$.

SINANPE: RCS

Herbarios peruanos: Ninguno.

Observaciones: Arbusto conocido solamente de la cuenca del Pachitea. Este taxón fue descrito de una planta recolectada en 1969 del área que hoy ocupa la Reserva Comunal del Sira. No se conoce la situación de sus poblaciones.

\section{Miconia cilianis Triana}

Publicación: Trans. Linn. Soc. London 28(1): 105.[1872]. 1871

Colección tipo: H. Ruiz \& J. Pavón 14/ 65

Hemarios: MA.

Nombre común: D esconocido.

Registro departamental: JU, SM.

Regiones Ecológicas: Sin datos; altitud desconocida.

SINAN PE: Sin registro.

Herbarios peruanos: Ninguno.
Observaciones: Este taxón fue considerado por Brako \& Zarucchi (1993) como un endemismo; sin embargo, no ha sido posible evaluarlo, ni asignarle una categoría.

\section{Miconia clivonum Wurdack}

Publicación: Phytologia 11(6): 388-389.

1965.

Colección tipo: J.J. Wurdack 1794

Herbarios: US; USM.

Nombre común: D esconocido.

Registro departamental: AM.

Regiones Ecológicas: BMHM; 2700$2800 \mathrm{~m}$.

SINAN PE: Sin registro.

Hemarios penuanos: USM (isotipo citado).

Observaciones: Arbusto conocido de una localidad en la cuenca del Utcubamba. No ha sido posible evaluarlo ni asignarle una categoná

\section{Miconia cookii Gleason}

Publicación: Phytologia 1(1): 43-44. 1933.

Colección tipo: O.F. Cook \& G.B. Gilbert 1742

Hemarios: US.

Nombre común: D esconocido.

Registro departamental: CU.

Regiones Ecológicas: BMHM; 1800 m.

SINAN PE: Sin registro.

Herbarios peruanos: Ninguno.

Observaciones: Esta especie tiene relaciones estrechas con la especie boliviana Mionnia elongata.

\section{Miconia crassifolia Triana}

Publicación: Trans. Linn. Soc. London 28(1): 125. [1872]. 1871

Colección tipo: A. Mathews s.n.

Herbarios: $G$.

Nombre común: D esconocido.

Registro departamental: AM.

Regiones Ecológicas: Sin datos; altitud desconocida.

SINAN PE: Sin registro.

Hemarios peruanos: Ninguno.

Observaciones: Este taxón fue considerado por Brako \& Zarucchi (1993) como un endemismo; sin embargo, no ha sido posible evaluarlo, ni asignarle una categoría.

\section{Miconia crassipes Triana}

Publicación: Trans. Linn. Soc. London 28(1): 116. [1872]. 1871

Colección tipo: A. Mathews 1300

Herbarios: K.

Nombre común: D esconocido.

Registro departamental: AM.

Regiones Ecológicas: $\mathrm{PAR}, \mathrm{BMHM}$; 2330-3100 m.

SINAN PE: Sin registro.

Herbarios penuanos: CPUN (1). 
Observaciones: Planta localmente escasa. Este taxón fue considerado por Brako \& Zarucchi (1993) como un endemismo; sin embargo, no ha sido posible evaluarlo, ni asignarle una categoría.

\section{Miconia crassistigma Cogn.}

Publicación: Bot. Jahrb. Syst. 42: 143 1908.

Colección tipo: A. Weberbauer 3407

Henbarios: B; MOL!

Nombre común: D esconocido.

Registro departamental: CA, HU.

Regiones Ecológicas: Sin datos; altitud desconocida.

SINANPE: Sin registro.

Herbarios penuanos: MOL (isotipo).

Observaciones: Este taxón fue considerado por Brako \& Zarucchi (1993) como un endemismo; sin embargo, no ha sido posible evaluarlo, ni asignarle una categoría.

\section{Miconia cremophylla Naudin}

Publicación: Ann. Sci. Nat., Bot., ser. 3, 16(2): 228. 1850.

Colección tipo: A. Mathews s.n.

Herbarios: $\mathrm{G}$.

Nombre común: D esconocido.

Registro departamental: AM, SM.

Regiones Ecológicas: Sin datos; altitud desconocida.

SINAN PE: Sin registro.

Herbarios peruanos: Ninguno.

Observaciones: Este taxón fue considerado por Brako \& Zarucchi (1993) como un endemismo; sin embargo, no ha sido posible evaluarlo, ni asignarle una categoría.

\section{Miconia dasyclada Wurdack}

Publicación: Phytologia 23(5): 492-493. 1972.

Colección tipo: T.R. Dudley 11829

Herbarios: NA, US.

Nombre común: D esconocido.

Registro departamental: AY, CU.

Regiones Ecológicas: BMHM; $1570 \mathrm{~m}$.

SINAN PE: Sin registro.

Hembarios peruanos: Ninguno.

Observaciones: Arbusto conocido de dos localidades en la cuenca del A purímac, una de ellas en una cordillera frente a la deVilcabamba. No ha sido posible evaluarlo, ni asignarle una categoría.

\section{Miconia demissifolia Wurdack}

Publicación: Phytologia 23(5): 489-491. 1972.

Colección tipo: M.T. Madison 10168-70

Henbarios: NA, US.

Nombre común: D esconocido.

Registro departamental: CU, PA.

Regiones Ecológicas: $\mathrm{BPM}, \mathrm{BMHM}$;

3300-3535 m.

SINAN PE: Sin registro.

Herbarios peruanos: Ninguno.
Observaciones: Árbol descrito de una planta recolectada en la Cordillera de Vilcabamba, cuenca del Apurímac. Este taxón fue considerado por Brako \& Zarucchi (1993) como un endemismo; sin embargo, no ha sido posible evaluarlo, ni asignarle una categoría.

\section{Miconia divisoniana Wurdack}

\section{CR, Bla}

Publicación: Phytologia 16(3): 175. 1968. Colección tipo: R. Ferreyra 1669

Hemarios: US; USM.

Nombre común: D esconocido.

Registro departamental: UC.

Regiones Ecológicas: BMHM; 1500$1600 \mathrm{~m}$.

SINAN PE: Sin registro.

Herbarios peruanos: USM (isotipo citado).

Observaciones: Arbusto conocido solamente de la cuenca del Aguaytía, al sur del límite del Parque Nacional Cordillera Azul. Esta especie presentaba poblaciones en el Boquerón del Padre Abad, pero aparentemente no ha vuelto a ser recolectada desde 1947.

\section{Miconia dumetosa Cogn.}

Publicación: Bot. Jahrb. Syst. 42: 144. 1908. Colección tipo: A. Weberbauer 4389

Hemarios: B; MOL!.

Nombre común: D esconocido.

Registro departamental: AM, HU, SM.

Regiones Ecológicas: BMHM; $2200 \mathrm{~m}$.

SINAN PE: Sin registro.

Hembarios peruanos: MOL (isotipo).

Observaciones: Este taxón fue considerado por Brako \& Zarucchi (1993) como un endemismo; sin embargo, no ha sido posible evaluarlo, ni asignarle una categoría

\section{Miconia egregia Wurdack}

\section{EN, Bla}

Publicación: Phytologia 39(5): 326-327. 1978.

Colección tipo: C. Sandeman 4086

Herbarios: $\mathrm{K}$.

Nombre común: D esconocido.

Registro departamental: CA.

Regiones Ecológicas: MA; 2700 m.

SINAN PE: Sin registro.

Hemarios penuanos: MOL (1).

Observaciones: Arbusto conocido de unas pocas localidades dispersas, en la vertiente occidental de Cajamarca. Al parecer, todas las colecciones provienen de la cuenca del Chancay. Las poblaciones conocidas fueron registradas en matorrales y fragmentos de bosque, ambientes afectados hoy en día por incendios y tala.

\section{Miconia expansa Gleason}

Publicación: Bull. Torrey Bot. Club 63(9): 536. 1936.

Colección tipo: G. Klug 3201

Henbarios: NY.

Nombre común: D esconocido.

Registro departamental: LO, MD.

Regiones Ecológicas: BMHP; 600- $1200 \mathrm{~m}$.

SINAN PE: Sin registro.

Herbarios peruanos: Ninguno. 
Observaciones: Este taxón fue considerado por Brako \& Zarucchi (1993) como un endemismo; sin embargo, no ha sido posible evaluarlo, ni asignarle una categoría.

\section{Miconia falcata Cogn.}

Publicación: Bot. Jahrb. Syst. 42: 139. 1908.

Colección tipo: A. Weberbauer 4998

Herbarios: B, US.

Nombre común: D esconocido.

Registro departamental: CU.

Regiones Ecológicas: BMHM; 1500 m.

SINANPE: Sin registro.

Herbarios peruanos: Ninguno.

Observaciones: Arbusto considerado por Brako \& Zarucchi (1993) como un endemismo; sin embargo, no ha sido posible evaluarlo, ni asignarle una categoría. Esta especie se conoce de la cuenca del Urubamba.

\section{Miconia ferreyrae Wurdack}

Publicación: Phytologia 7(5): 235-236. 1960. Colección tipo: R. Ferreyra 4297

Hemarios: US; USM!

Nombre común: D esconocido.

Registro departamental: UC.

Regiones Ecológicas: BMHP; $1300-$ $1400 \mathrm{~m}$.

SINANPE: Sin registro.

Herbarios penuanos: USM (isotipo).

Observaciones: Esta especie se conoce solamente del límite entre Ucayali y Huánuco. Brako \& Zarucchi (1993) listaron San Martín, pero este es un error que repite la citación de la descripción original.

\section{Miconia firma J.F. Macbr.}

$$
\text { EN, Bla }
$$

Publicación: Field Mus. Nat. Hist., Bot. Ser. 13(4/ 1): 411. 1941.

Colección tipo: A. Weberbauer 6389

Herbarios: $F$.

Nombre común: D esconocido.

Registro departamental: CA, PI.

Regiones Ecológicas: MA; altitud desconocida.

SINAN PE: Sin registro

Herbarios peruanos: Ninguno.

Observaciones: Planta perenne conocida de unas pocas localidades en el norte de la vertiente del Paćfico. Macbride (1941) indicó a Cajamarca como el D epartamento donde fue recolectado el ejemplar tipo, pero en realidad corresponde a Piura. Brako \& Zarucchi (1993), como indica Hensold (1999), no indicaron que se trataba de un endemismo.

\section{Miconia floccosa Cogn.}

\section{VU, Bla}

Publicación: Bot. Jahrb. Syst. 42: 140. 1908. Colección tipo: A. Weberbauer 2200

Herbarios: B; MOL!.

Nombre común: D esconocido.

Registro departamental: JU, PA.

Regiones Ecológicas: $\mathrm{BPM}, \mathrm{BMHM}$; 3000-3500 m.

SINANPE: PNYC

Herbarios peruanos: MOL (isotipo), MOLF (1), USM (1).
Observaciones: Árbol de flores amarillas, recolectado originalmente en 1903, en los bosques fragmentados al oeste de Huacapistana. Aparentemente está restringida al centro del país y está representada en el sistema de áreas protegidas. Se halla en las cuencas del Huancabamba y del Perené.

\section{Miconia fruticulosa Cogn.}

$$
\text { CR, Blab(iii) }
$$

Publicación: Bot. Jahrb. Syst. 42: 146. 1908.

Colección tipo: A. Weberbauer 3383

Hemarios: B, US.

Nombre común: D esconocido.

Registro departamental: $\mathrm{HU}$.

Regiones Ecológicas: BPM; 3400 m.

SINAN PE: Sin registro.

Herbarios peruanos: Ninguno.

Observaciones: Arbusto conocido solamente de la cuenca del Monzón, una de las áreas con mayor necesidad de estudio botánico. Esta especie fue descrita de una planta recolectada en 1903 y si bien en décadas posteriores se realizaron colecciones en la cuenca del Huallaga no fue registrada esta especie. Amenazas a las poblaciones en el valle del Monzón están asociadas a la deforestación.

\section{Miconia glomerata Triana}

Publicación: Trans. Linn. Soc. London 28(1): 110. [1872] 1871.

Colección tipo: H. Ruiz \& J. Pavón 14/ 58

Herbarios: P.

Nombre común: Desconocido.

Registro departamental: AY, CU, HU, PA.

Regiones Ecológicas: $\mathrm{BMHM}$; 1000 $2000 \mathrm{~m}$.

SINAN PE: Sin registro.

Hembarios peruanos: Ninguno.

Observaciones: Este taxón fue considerado por Brako \& Zarucchi (1993) como un endemismo; sin embargo, no ha sido posible evaluarlo, ni asignarle una categoría.

\section{Miconia glutinosa Cogn.}

Publicación: Bot. Jahrb. Syst. 42: 141. 1908. Colección tipo: A. Weberbauer 1325

Herbarios: B, US.

Nombre común: D esconocido.

Registro departamental: PU.

Regiones Ecológicas: BMHM; 2400 m.

SINAN PE: Sin registro.

Herbarios peruanos: Ninguno.

Observaciones: Este taxón fue considerado por Brako \& Zarucchi (1993) como un endemismo; sin embargo, no ha sido posible evaluarlo, ni asignarle una categoría.

\section{Miconia griffisii J.F. Macbr.}

Publicación: Publ. Field Columbian Mus., Bot. Ser. 4: 188. 1929.

Colección tipo: J.F. Macbride 4382

Herbarios: F.

Nombre común: D esconocido.

Registro departamental: HU, SM.

Regiones Ecológicas: Sin datos; altitud desconocida.

SINANPE: Sin registro.

Hembarios peruanos: Ninguno. 
Observaciones: Este taxón fue considerado por Brako \& Zarucchi (1993) como un endemismo; sin embargo, no ha sido posible evaluarlo, ni asignarle una categoría.

\section{Miconia grisea Cogn.}

\section{CR, Bla}

Publicación: Bot. Jahrb. Syst. 42: 147. 1908. Colección tipo: A. Weberbauer 3346

Herbarios: B; MOL!

Nombre común: D esconocido.

Registro departamental: HU.

Regiones Ecológicas: BPM; $3400 \mathrm{~m}$.

SINAN PE: Sin registro.

Herbarios penuanos: MOL (isotipo).

Observaciones: Este arbusto es conocido solamente de los fragmentos de bosque en la cuenca alta del Monzón, localidad que debería ser de interés herborizar y estudiar, por albergar una interesante y rica flora endémica. Esta especie no ha vuelto a ser recolectada desde 1903.

\section{Miconia hamata Cogn.}

Publicación: Bot. Jahrb. Syst. 42: 141. 1908.

Colección tipo: A. Weberbauer 4447

Henbarios: MOL!.

Nombre común: D esconocido.

Registro departamental: AM.

Regiones Ecológicas: BMHM; $2200 \mathrm{~m}$.

SINANPE: Sin registro.

Herbarios penuanos: MOL (isotipo).

Observaciones: Este taxón fue considerado por Brako \& Zarucchi (1993) como un endemismo; sin embargo, no ha sido posible evaluarlo, ni asignarle una categoría.

\section{Miconia heteromera Naudin}

Publicación: Ann. Sci. Nat., Bot., ser. 3, 16(2): 124. 1850.

Colección tipo: E.F. Poeppig s.n.

Herbarios: P.

Nombre común: D esconocido.

Registro departamental: HU, LO, PA, SM.

Regiones Ecológicas: BHA; 120.

SINAN PE: Sin registro.

Hemarios peruanos: Ninguno.

Observaciones: Este taxón fue considerado por Brako \& Zarucchi (1993) como un endemismo; sin embargo, no ha sido posible evaluarlo, ni asignarle una categoría.

\section{Miconia hexapetalaWurdack}

$$
\text { EN, Blab(iii) }
$$

Publicación: Phytologia 48(3): 240. 1981. Colección tipo: J. Schunke V. 11432

Herbarios: DUKE, F, TEX, US; AMAZ! USM.

Nombre común: D esconocido.

Registro departamental: HU, PA.

Regiones Ecológicas: BMHM, BMHP; 1450- $2500 \mathrm{~m}$.

SINAN PE: Sin registro.

Hembarios penuanos: AMAZ (isotipo+1), USM (isotipo citado).
Observaciones: Arbusto conocido de las cuencas del Aguaytía e Iscozacín. La localidad tipo está ubicada muy cerca al Parque Nacional CordilleraAzul y es probable que esté representada en este Parque.

\section{Miconia histothrix Wurdack}

Publicación: Brittonia 40(1): 12-13. 1988.

Colección tipo: J. Schunke V. 7553

Herbarios: MO, US.

Nombre común: D esconocido.

Registro departamental: SM.

Regiones Ecológicas: BMHP; 800-850 m.

SINAN PE: Sin registro.

Hembarios peruanos: Ninguno.

Observaciones: Esta especie arbustiva fue reconocida porWurdack (1988) de una planta recolectada en la cuenca del río Huallaga. No ha sido posible evaluarla, ni asignarle una categoría.

\section{Miconia hospitalis Wurdack}

$$
\text { VU, Bla }
$$

Publicación: Phytologia 23(5): 475. 1972.

Colección tipo: C.O. Schunke A 20

Herbarios: US.

Nombre común: D esconocido.

Registro departamental: $\mathrm{AY}, \mathrm{HU}, \mathrm{JU}$.

Regiones Ecológicas: $\mathrm{BMHM}, \mathrm{BMHP}$; $1300-1700 \mathrm{~m}$.

SINANPE: RCS

Hembarios peruanos: Ninguno.

Observaciones: Árbol conocido del centro del país, de las cuencas del Tulumayo y Pachitea. Esta especie está también representada en la Reserva Comunal El Sira, en donde fue recolectada en 1969.

\section{Miconia huanucensis Wurdack}

Publicación: Phytologia 24(3): 201. 1972. Colección tipo: E. Asplund 13173

Herbarios: S.

Nombre común: D esconocido.

Registro departamental: HU.

Regiones Ecológicas: Sin datos; altitud desconocida.

SINAN PE: Sin registro.

Herbarios peruanos: Ninguno.

Observaciones: Este taxón fue considerado por Brako \& Zarucchi (1993) como un endemismo; sin embargo, no ha sido posible evaluarlo, ni asignarle una categoría.

\section{Miconia hutchisonii Wurdack}

Publicación: Phytologia 14(5): 273. 1967. Colección tipo: P.C. Hutchison \& J.K. Wright 6638

Hemanios: UC, US; USM.

Nombre común: D esconocido.

Registro departamental: PI.

Regiones Ecológicas: MA; 2650-3200 m.

SINAN PE: Sin registro.

Herbarios peruanos: HUT (1), USM (isotipo citado). 
Observaciones: Este taxón fue considerado por Brako \& Zarucchi (1993) como un endemismo; sin embargo, no ha sido posible evaluarlo, ni asignarle una categoría.

\section{Miconia icosandra Gleason}

\section{NE}

Publicación: Bull. Torrey Bot. Club 58: 239. 1931.

Colección tipo: E.P. Killip \& A.C. Smith 26781

Hemanios: NY, US.

Nombre común: D esconocido.

Registro departamental: HU, PA.

Regiones Ecológicas: BMHM; 1600$1900 \mathrm{~m}$.

SINANPE: Sin registro.

Herbarios peruanos: Ninguno.

Observaciones: Árbol, conocido del centro del país, aunque un ejemplar procedente de México es reconocido como esta especie (ver TRO PICOS). El ejemplar tipo fue recolectado en la cuenca del Pichis, en el D epartamento de Pasco.

\section{Miconia integrifolia Cogn.}

Publicación: Monogr. Phan. 7: 936. 1891. Colección tipo: H. Ruiz \& J. Pavón s.n.

Henbarios: G-DC.

Nombre común: D esconocido.

Registro departamental: SM.

Regiones Ecológicas: Sin datos; altitud desconocida.

SINANPE: Sin registro.

Herbarios peruanos: Ninguno.

Observaciones: Este taxón fue considerado por Brako \& Zarucchi (1993) como un endemismo; sin embargo, no ha sido posible evaluarlo, ni asignarle una categoría.

\section{Miconia koepckeana Wurdack}

$$
\text { EN, Bla }
$$

Publicación: Phytologia 23(5): 485. 1972.

Colección tipo: T.R. Dudley 13143

Hembarios: NA, US.

Nombre común: D esconocido.

Registro departamental: HU.

Regiones Ecológicas: BMHP; $1000 \mathrm{~m}$.

SINANPE: RCS

Herbarios peruanos: USM (1).

Observaciones: Arbusto conocido solamente de la cuenca del Pachitea. Esta especie fue descrita de una planta recolectada en 1969, de la Reserva Comunal El Sira, donde ocupa bosques de altura cortay que por su ubicación están afectados por deforestación.

\section{Miconia lachnoclada Wurdack}

$$
\text { CR, Bla }
$$

Publicación: Phytologia 23(5): 501. 1972.

Colección tipo: M.T. Madison 10378

Hembarios: NA, US.

Nombre común: D esconocido.

Registro departamental: AY.

Regiones Ecológicas: PSH, BPM; 3587 m.

SINANPE: Sin registro.

Herbarios peruanos: Ninguno.
Observaciones: Árbol conocido solamente de una localidad en la cuenca del A purímac. Esta especie fue recolectada de una población ubicada frente a la Cordillera de Vilcabamba y ocupando zonas ecotonales de puna a bosque montano.

\section{Miconia laciniata Wurdack}

\section{CR, B lab(iii)}

Publicación: Phytologia 69(5): 320-321. 1990.

Colección tipo: A. Sagástegui A. et al. 12994

Herbarios: F, US; HUT!

Nombre común: Desconocido.

Registro departamental: CA.

Regiones Ecológicas: MDE; 2000 m.

SINAN PE: Sin registro.

Hemarios penuanos: HUT (isotipo).

Observaciones: Arbusto conocido, al parecer, sólo de unalocalidad (Hensold, 1999), en la vertiente occidental del sur de Cajamarca, en una subcuenca del Chancay. Fue registrada en una zona ecotonal entre matorral y bosque fragmentado, ambientes amenazados por tala para leña y expansión agrícola.

\section{Miconia lambayequensis Wurdack}

\section{DD}

Publicación: Phytologia 64(4): 297. 1988.

Colección tipo: S. Llatas Q. 1976

Herbarios: F, US.

Nombre común: Desconocido.

Registro departamental: LA.

Regiones Ecológicas: MDE; 2000 m.

SINAN PE: Sin registro.

Hemarios peruanos: Ninguno.

Observaciones: Arbusto conocido solamente de una localidad en la cuenca del Olmos en la vertiente occidental. Se desconoce las condiciones de sus poblaciones.

\section{Miconia lechleni Triana}

Publicación: Trans. Linn. Soc. London 28(1): 124. [1872]. 1871.

Colección tipo: W. Lechler 2562

Herbarios: Sin datos.

Nombre común: D esconocido.

Registro departamental: PU.

Regiones Ecológicas: Sin datos; altitud desconocida.

SINANPE: Sin registro.

Herbarios peruanos: Ninguno.

Observaciones: Estetaxón fue considerado por Brako \& Zarucchi (1993) como un endemismo; sin embargo, no ha sido posible evaluarlo, ni asignarle una categoría.

\section{Miconia lilacina Triana}

Publicación: Trans. Linn. Soc. London 28(1): 129. [1872]. 1871

Colección tipo: R.W. Pearce s.n.

Herbarios: $\mathrm{K}$.

Nombre común: Desconocido.

Registro departamental: CU, PA.

Regiones Ecológicas: Sin datos; altitud desconocida.

SINANPE: Sin registro.

Hembarios peruanos: Ninguno. 
Observaciones: Este taxón fue considerado por Brako \& Zarucchi (1993) como un endemismo; sin embargo, no ha sido posible evaluarlo, ni asignarle una categoría.

\section{Miconia longiracemosa Gleason}

Publicación: Bull. Torrey Bot. Club 58: 232. 1931.

Colección tipo: L. Williams 4249

Herbarios: US.

Nombre común: D esconocido.

Registro departamental: LO.

Regiones Ecológicas: BHA; 155- 210 m.

SINAN PE: Sin registro.

Herbarios peruanos: Ninguno.

Observaciones: Este taxón fue considerado por Brako \& Zarucchi (1993) como un endemismo; sin embargo, no ha sido posible evaluarlo, ni asignarle una categoría.

\section{Miconia loretensis Pilg.}

Publicación: Verh. Bot. Vereins Prov. Brandenburg 47: 172. 1905.

Colección tipo: E.H.G. Ule 6734

Herbarios: B.

Nombre común: D esconocido.

Registro departamental: SM.

Regiones Ecológicas: BMHP; $1400 \mathrm{~m}$.

SINANPE: ACRCE

Herbarios peruanos: Ninguno.

Observaciones: Este taxón fue considerado por Brako \& Zarucchi (1993) como un endemismo; sin embargo, no ha sido posible evaluarlo, ni asignarle una categoría.

\section{Miconia lugubris Cogn.}

Publicación: Bot. Jahrb. Syst. 42: 142. 1908.

Colección tipo: A. Weberbauer 3394

Herbarios: B, US; MOL!

Nombre común: D esconocido.

Registro departamental: HU.

Regiones Ecológicas: Sin datos; altitud desconocida.

SINAN PE: Sin registro.

Herbarios peruanos: MOL (isotipo).

Observaciones: Este taxón fue considerado por Brako \& Zarucchi (1993) como un endemismo; sin embargo, no ha sido posible evaluarlo, ni asignarle una categoría.

\section{Miconia lutescens (Bonpl.) DC. subsp. piurensis Wurdack}

\section{EN, B lab(iii)}

Publicación: Phytologia 5(2): 59. 1954

Colección tipo: C. Ochoa 1753

Herbanios: NY.

Nombre común: D esconocido.

Registro departamental: PI

Regiones Ecológicas: MA; 1800-2200 m.

SINAN PE: Sin registro.

Henbarios penuanos: CPUN (1), HAO (1).
Observaciones: Arbusto conocido de dos localidades, en los alrededores de un fragmento de bosque, cerca de Ayabaca. Al igual que otros taxones de los fragmentos de bosque en la vertiente occidental, amenazas a sus poblaciones provienen dela deforestación.

\section{Miconia madisonii Wurdack}

Publicación: Phytologia 23(5): 482-483. 1972.

Colección tipo: M.T. Madison 10295

Henbarios: MO, US.

Nombre común: Desconocido.

Registro departamental: AY.

Regiones Ecológicas: BMHM; $2224 \mathrm{~m}$.

SINANPE: Sin registro.

Herbarios peruanos: Ninguno.

Observaciones: Arbusto conocido solamente de una población, localmente frecuente, que ocupaba un bosque nublado, en la cuenca del A purímac. No ha sido posible evaluarlo, ni asignarle una categoría.

\section{Miconia malatestae J.F. Macbr.}

Publicación: Publ. Field Columbian Mus., Bot. Ser. 4: 181. 1929.

Colección tipo: J.F. Macbride 5176

Herbarios: $F$

Nombre común: D esconocido.

Registro departamental: HU, PA.

Regiones Ecológicas: Sin datos; altitud desconocida.

SINAN PE: Sin registro.

Herbarios peruanos: Ninguno.

Observaciones: Este taxón fue considerado por Brako \& Zarucchi (1993) como un endemismo; sin embargo, no ha sido posible evaluarlo, ni asignarle una categoría.

\section{Miconia media (D. Don) Naudin subsp. borealis Wurdack}

VU, Bla

Publicación: Phytologia 9(7): 421. 1964. Colección tipo: J.J. Wurdack 1265

Herbarios: US; USM.

Nombre común: D esconocido.

Registro departamental: AM, CA.

Regiones Ecológicas: $\mathrm{MA}, \mathrm{BMHM}$; 2400- $2875 \mathrm{~m}$

SINAN PE: Sin registro.

Herbarios penuanos: HAO (1).

Observaciones: Arbusto descrito de una planta recolectada en 1962, de las laderas orientales de los Cerros Calla Calla, localidad que alberga varios endemismos y ubicada en una subcuenca del Marañón. También es conocida de fragmentos de bosque en la la vertiente occidental. 
117. Miconia media (D. Don) Naudin subsp. cajamarcensis Wurdack

VU, Bla

Publicación: Phytologia 14(5): 274. 1967. Colección tipo: P.C. Hutchison \& J.K. Wright 5028

Hembarios: US; USM.

Nombre común: Mote mote negro.

Registro departamental: CA.

Regiones Ecológicas: MA; 2630-3050 m.

SINANPE: Sin registro.

Herbarios peruanos: HUT (1), USM (isotipo citado).

Observaciones: Arbusto conocido de varias localidades dispersas, entre las cuencas del Magdalenay del Saña, en la vertiente occidental del sur de Cajamarca, en donde ha sido registrado en diferentes años. Este taxón fue hallado en poblaciones grandes, con numerosos individuos.

\section{Miconia membranacea Triana}

Publicación: Trans. Linn. Soc. London 28(1): 115. [1871]. 1872.

Colección tipo: H. Ruiz \& J. Pavón s.n.

Hembarios: B.

Nombre común: D esconocido.

Registro departamental: HU, LO, PA, SM. Regiones Ecológicas: BMHP; 450-900 m.

SINAN PE: Sin registro.

Herbarios peruanos: Ninguno.

Observaciones: Este taxón fue considerado por Brako \& Zarucchi (1993) como un endemismo; sin embargo, no ha sido posible evaluarlo, ni asignarle una categoría.

119. Miconia miles-morganiiJ.F. Macbr.

Publicación: Publ. Field Columbian Mus., Bot. Ser. 4: 184. 1929.

Colección tipo: J.F. Macbride 4318

Hembarios: F, US.

Nombre común: D esconocido.

Registro departamental: $\mathrm{AM}, \mathrm{HU}$.

Regiones Ecológicas: BMHM; 2400$3100 \mathrm{~m}$.

SINAN PE: Sin registro.

Herbarios peruanos: Ninguno.

Observaciones: Este taxón fue considerado por Brako \& Zarucchi (1993) como un endemismo; sin embargo, no ha sido posible evaluarlo, ni asignarle una categoría.

120. Miconia modica J.F. Macbr.

Publicación: Publ. Field Columbian Mus., Bot. Ser. 4: 182. 1929.

Colección tipo: A. Weberbauer 7552

Hemarios: F, NY.

Nombre común: D esconocido.

Registro departamental: AY.

Regiones Ecológicas: BPM; 2800- 2900 m.

SINANPE: Sin registro.

Herbarios peruanos: Ninguno.
Observaciones: Este taxón fue considerado por Brako \& Zarucchi (1993) como un endemismo; sin embargo, no ha sido posible evaluarlo, ni asignarle una categoría.

\section{Miconia molinopampa Wurdack}

EN, Bla

Publicación: Phytologia 13(2): 78- 79. 1966.

Colección tipo: J.J. Wurdack 1389a

Hemarios: US; USM.

Nombre común: D esconocido.

Registro departamental: AM.

Regiones Ecológicas: BMHM; 2400$2450 \mathrm{~m}$.

SINAN PE: Sin registro.

Herbarios peruanos: USM (isotipo citado).

Observaciones: Arbusto conocido de matorrales en la cuenca del Utcubamba; donde, aparentemente, no ha vuelto a ser recolectada desde 1962. Las poblaciones conocidas fueron descritas con individuos dispersos. Incendios intencionales y actividades agrícolas podrían ser amenazas.

\section{Miconia mollis Triana}

Publicación: Trans. Linn. Soc. London 28(1): 113. [1872]. 1871.

Colección tipo: R. Spruce 4177

Herbarios: C, US.

Nombre común: D esconocido.

Registro departamental: SM.

Regiones Ecológicas: BMHP; 500- $1000 \mathrm{~m}$.

SINANPE: Sin registro.

Herbarios peruanos: Ninguno.

Observaciones: Este taxón fue considerado por Brako \& Zarucchi (1993) como un endemismo; sin embargo, no ha sido posible evaluarlo, ni asignarle una categoría.

\section{Miconia monzoniensisCogn. subsp. cuzcoensisWurdack}

Publicación: Phytologia 23(5): 484-485. 1972.

Colección tipo: M.T. Madison 10147

Herbarios: NA.

Nombre común: D esconocido.

Registro departamental: CU, PA.

Regiones Ecológicas: BMHM; $2568 \mathrm{~m}$.

SINANPE: PNO

Herbarios peruanos: Ninguno.

Observaciones: Estetaxón fue considerado por Brako \& Zarucchi (1993) como un endemismo; sin embargo, no ha sido posible evaluarlo, ni asignarle una categoría.

\section{Miconia neniifolia Triana brevifolia Cogn.}

Publicación: Bot. Jahrb. Syst. 42: 143. 1908. Colección tipo: A. Weberbauer 3356

Hemarios: B.

Nombre común: D esconocido.

Registro departamental: CA, CU, HU.

Regiones Ecológicas: Sin datos; altitud desconocida.

SINAN PE: Sin registro.

Herbarios peruanos: Ninguno. 
Observaciones: Este taxón fue considerado por Brako \& Zarucchi (1993) como un endemismo; sin embargo, no ha sido posible evaluarlo, ni asignarle una categoría.

\section{Miconia nigricans Cogn.}

Publicación: Bot. Jahrb. Syst. 42: 146. 1908. Colección tipo: A. Weberbauer 4392

Herbarios: B, US.

Nombre común: D esconocido.

Registro departamental: AM, HU.

Regiones Ecológicas: $\mathrm{BPM}, \mathrm{BMHM}$; 2400-3100 m.

SINANPE: Sin registro.

Hembarios peruanos: Ninguno.

Observaciones: Este taxón fue considerado por Brako \& Zarucchi (1993) como un endemismo; sin embargo, no ha sido posible evaluarlo, ni asignarle una categoría.

\section{Miconia nobilis Gleason}

\section{DD}

Publicación: Bull. Torrey Bot. Club 58: 235-236. 1931.

Colección tipo: E.P. Killip \& A.C. Smith 26006

Hemarios: NY, US.

Nombre común: D esconocido.

Registro departamental: PA.

Regiones Ecológicas: BMHP; 1100 m.

SINANPE: Sin registro.

Herbarios peruanos: Ninguno.

Observaciones: Arbusto recolectado en la cuenca del Pichis, muy cerca al límite departamental con Junín; al parecer, no ha vuelto a ser recolectada desde 1929 .

\section{Miconia opacifolia J.F. Macbr.}

Publicación: Publ. Field Columbian Mus., Bot. Ser. 4: 184. 1929.

Colección tipo: J.F. Macbride 5197

Herbarios: $F$.

Nombre común: D esconocido.

Registro departamental: HU, PA.

Regiones Ecológicas: BMHM; $2450 \mathrm{~m}$.

SINAN PE: Sin registro.

Herbarios peruanos: Ninguno.

Observaciones: Este taxón fue considerado por Brako \& Zarucchi (1993) como un endemismo; sin embargo, no ha sido posible evaluarlo, ni asignarle una categoría.

128. Miconia ottikeniJ.F. Macbr.

$$
\text { CR, Bla }
$$

Publicación: Publ. Field Columbian Mus. Bot. Ser. 4: 185. 1929.

Colección tipo: J.F. Macbride 4430

Herbarios: F, NY.

Nombre común: D esconocido.

Registro departamental: HU.

Regiones Ecológicas: PSH; 3900 m.

SINAN PE: Sin registro.

Herbarios peruanos: Ninguno.
Observaciones: Esta especie arbustiva se conoce solamente de una localidad, ubicada en el centro del país, en la cuenca alta del río Huallaga. Esta área ha sido poco herborizada y por ello, el escaso conocimiento sobre esta especie.

\section{Miconia paradisiaca Wurdack}

$$
\text { CR, Bla }
$$

Publicación: Phytologia 11(6): 391- 392. 1965.

Colección tipo: J.J. Wurdack 1055

Herbarios: US; USM.

Nombre común: D esconocido.

Registro departamental: AM.

Regiones Ecológicas: BMHM; 2200$2300 \mathrm{~m}$.

SINAN PE: Sin registro.

Herbarios penuanos: USM (isotipo citado).

Observaciones: Arbusto conocido de la cuenca alta del Chiriaco. Wurdack (1965) considero que esta especie era probablemente dioica, por lo que si se confirma sus poblaciones estarían muy afectadas por fragmentación de su hábitat.

\section{Miconia pauciglandulosa Naudin}

Publicación: Ann. Sci. Nat., Bot., ser. 3, 16(2): 183. 1851.

Colección tipo: E.F. Poeppig s.n.

Herbarios: Sin datos.

Nombre común: D esconocido.

Registro departamental: HU.

Regiones Ecológicas: Sin datos; altitud desconocida.

SINAN PE: Sin registro.

Herbarios peruanos: Ninguno.

Observaciones: Este taxón fue considerado por Brako \& Zarucchi (1993) como un endemismo; sin embargo, no ha sido posible evaluarlo, ni asignarle una categoría.

\section{Miconia polychaeta Wurdack}

Publicación: Phytologia 23(5): 493-494. 1972.

Colección tipo: T.R. Dudley 10430

Hemarios: NA, US.

Nombre común: D esconocido.

Registro departamental: CU, SM.

Regiones Ecológicas: BMHM; 1730$2000 \mathrm{~m}$

SINAN PE: Sin registro.

Herbarios peruanos: Ninguno.

Observaciones: Árbol dioico conocido de localidades dispersas en la vertiente oniental. No hasido posible evaluarlo, ni asignarleuna categoná.

\section{Miconia polytopica Wurdack}

\section{DD}

Publicación: Phytologia 23(5): 478. 1972. Colección tipo: T.R. Dudley 10346

Hemanios: NA, US.

Nombre común: D esconocido.

Registro departamental: $\mathrm{AM}, \mathrm{AY}, \mathrm{CU}, \mathrm{HU}$. Regiones Ecológicas: BMHM; $1730 \mathrm{~m}$.

SINANPE: RCS, ZRSC

Herbarios peruanos: USM (2). 
Observaciones: Especie arbustiva reconocida aquí en un sentido taxonómico amplio. Al parecer, conocida de poblaciones dispersas, en las cuencas del Cenepa, Pachitea y Apurímac. Es probable que esté representada en la flora ecuatoriana.

\section{Miconia pulgariJ.F. Macbr.}

Publicación: Publ. Field Columbian Mus., Bot. Ser. 4: 182. 1929.

Colección tipo: J.F. Macbride 4145

Herbarios: F, NY.

Nombre común: D esconocido.

Registro departamental: HU.

Regiones Ecológicas: BMHM; $1780 \mathrm{~m}$.

SINANPE: Sin registro.

Herbarios peruanos: Ninguno.

Observaciones: Este taxón fue considerado por Brako \& Zarucchi (1993) como un endemismo; sin embargo, no ha sido posible evaluarlo, ni asignarle una categoría.

\section{Miconia punicea Wurdack}

Publicación: Phytologia 23(5): 480-481. 1972.

Colección tipo: T.R. Dudley 10663

Herbarios: US.

Nombre común: D esconocido.

Registro departamental: CU.

Regiones Ecológicas: BMHM; 1730$2350 \mathrm{~m}$.

SINANPE: Sin registro.

Herbarios peruanos: Ninguno.

Observaciones: Arbusto conocido de poblaciones grandes en la Cordillera de Vilcabamba, en la cuenca del Apurímac. No ha sido posible evaluarlo, ni asignarle una categoría.

\section{Miconia quadrifolia Naudin}

Publicación: Ann. Sci. Nat., Bot., ser. 3, 16(2): 223. 1850.

Colección tipo: A. Mathews 1724

Herbarios: P, NY.

Nombre común: D esconocido.

Registro departamental: HU, JU.

Regiones Ecológicas: Sin datos; altitud desconocida.

SINAN PE: Sin registro.

Herbarios peruanos: Ninguno.

Observaciones: Este taxón fue considerado por Brako \& Zarucchi (1993) como un endemismo; sin embargo, no ha sido posible evaluarlo, ni asignarle una categoría.

\section{Miconia reflexipila Wurdack}

Publicación: Phytologia 23(5): 476-477. 1972.

Colección tipo: T.R. Dudley 13224

Herbarios: US.

Nombre común: D esconocido.

Registro departamental: CU, HU, PA.

Regiones Ecológicas: BMHP; 1290$1330 \mathrm{~m}$.

SINANPE: RCS

Herbarios peruanos: Ninguno.
Observaciones: Planta arbustiva descrita de un ejemplar recolectado en la Reserva Comunal El Sira, en la cuenca del Pachitea. No ha sido posible evaluarlo, ni asignarle una categoría.

\section{Miconia nufiramea Wurdack}

\section{DD}

Publicación: Phytologia 23(5): 496-497.

1972.

Colección tipo: T.R. Dudley 10919

Herbarios: NA, US.

Nombre común: D esconocido.

Registro departamental: CU.

Regiones Ecológicas: BPM; 2663-3000 m.

SINAN PE: Sin registro.

Herbarios peruanos: Ninguno.

Observaciones: Arbusto conocido sólo de la cuenca del Apurímac. El ejemplar tipo fue recolectado en 1968, de la Cordillera Vilcabamba, en la cima de de ésta, donde era localmente frecuente en áreas abiertas del bosque nublado.

\section{Miconia saltuensis Wurdack}

$$
\text { EN, B 1ab(iii) }
$$

Publicación: Phytologia 14(5): 272-273. 1967.

Colección tipo: P.C. Hutchison et al. 5935

Hemarios: UC, US; USM.

Nombre común: D esconocido.

Registro departamental: HU.

Regiones Ecológicas: BMHM; 2800 m.

SINANPE: Sin registro.

Herbarios peruanos: USM (isotipo citado+1).

Observaciones: Arbusto conocido de unas pocas poblaciones en la cuenca del Huallaga. Fue descrita de una planta recolectada en Carpish, localidad que alberga varios endemismos, pero está afectada por la deforestación. Al parecer, no ha vuelto a ser recolectada desde 1964.

\section{Miconia saxatilisJ.F. Macbr.}

Publicación: Publ. Field Columbian Mus., Bot. Ser. 4(8): 186. 1929

Colección tipo: J.F. Macbride 4881

Herbarios:

Nombre común: D esconocido.

Registro departamental: $\mathrm{HU}$.

Regiones Ecológicas: BPM; 2740 m.

SINAN PE: Sin registro.

Herbarios peruanos: Ninguno.

Observaciones: Este taxón fue considerado por Brako \& Zarucchi (1993) como un endemismo; sin embargo, no ha sido posible evaluarlo, ni asignarle una categoría.

\section{Miconia secundifolia Cogn. subsp. secundifolia}

Publicación:

Colección tipo: A. Weberbauer 4427

Hembarios: $B$.

Nombre común: D esconocido.

Registro departamental: AM.

Regiones Ecológicas: BMHM; 2200 m.

SINANPE: Sin registro.

Herbarios peruanos: Ninguno. 
Observaciones: Este taxón fue considerado por Brako \& Zarucchi (1993) como un endemismo; sin embargo, no ha sido posible evaluarlo, ni asignarle una categoría.

\section{Miconia secundifolia Cogn. subsp. malcabalensis Wurdack}

Publicación: Phytologia 11(6): 396. 1965.

Colección tipo: J.J. Wurdack 1419

Herbarios: NY, US.

Nombre común: D esconocido.

Registro departamental: AM.

Regiones Ecológicas: BPM; 2900 m.

SINAN PE: Sin registro.

Herbarios peruanos: Ninguno.

Observaciones: Este taxón fue considerado por Brako \& Zarucchi (1993) como un endemismo; sin embargo, no ha sido posible evaluarlo, ni asignarle una categoría.

\section{Miconia semisterilis Gleason}

\section{DD}

Publicación: Bull. Torrey Bot. Club 63: 535. 1936.

Colección tipo: G. Klug 3224

Hembarios: F, US.

Nombre común: D esconocido.

Registro departamental: AM, LO.

Regiones Ecológicas: BMHP; altitud desconocida.

SINANPE: Sin registro.

Herbarios peruanos: Ninguno.

Observaciones: Árbol conocido, al parecer, sólo de la localidad original en la cuenca del Huallaga, en donde fue recolectado en 1933. Una población adicional es conocida de la cuenca del Santiago. Una planta recolectadaen el Ecuador hasido consideradamuy cercanaa estaespecie.

\section{Miconia spichigeni Wurdack}

\section{DD}

Publicación: Candollea 44(2): 517. 1989. Colección tipo: R. Spichiger et al. 2000

Herbarios: G, US.

Nombre común: Rifarillo.

Registro departamental: LO.

Regiones Ecológicas: BHA; 100-150 m.

SINAN PE: Sin registro.

Herbarios peruanos: Ninguno.

Observaciones: Árbol o arbusto conocido, al parecer, sólo de dos localidades en las cuencas del Amazonas y Ucayali. Spichiger et al. (1990) señalaron que crece en el Arboreto Jenaro Herrera, en el sotobosque de áreas no inundables.

\section{Miconia subglabraCogn.}

Publicación: Fl. Bras. 14(4): 412. 1888.

Colección tipo: R. Spruce 4842

Henbarios: B, NY.

Nombre común: D esconocido.

Registro departamental: SM.

Regiones Ecológicas: BHA; 350 m.

SINANPE: Sin registro.

Henbarios peruanos: Ninguno.
Observaciones: Este taxón fue considerado por Brako \& Zarucchi (1993) como un endemismo; sin embargo, no ha sido posible evaluarlo, ni asignarle una categoría.

\section{Miconia subulipetala Wurdack}

\section{DD}

Publicación: Phytologia 48(3): 245- 246. 1981.

Colección tipo: M. Rimachi 3421

Hemanios: IBE, US; AMAZ!

Nombre común: Rifarillo.

Registro departamental: LO.

Regiones Ecológicas: BHA; altitud desconocida.

SINAN PE: Sin registro.

Herbarios penuanos: AMAZ (isotipo).

Observaciones: Árbol pequeño, de hasta $8 \mathrm{~m}$ de alto, conocido de una subcuenca del Nanay; al parecer, no ha vuelto a ser recolectada desde 1978.

146. Miconia sulcataJ.F. Macbr.

Publicación: Publ. Field Columbian Mus., Bot. Ser. 4(8): 186. 1929.

Colección tipo: C.O. Schunke 423

Hemarios: $F$.

Nombre común: D esconocido.

Registro departamental: JU.

Regiones Ecológicas: Sin datos; altitud desconocida.

SINAN PE: Sin registro.

Herbarios peruanos: Ninguno.

Observaciones: Este taxón fue considerado por Brako \& Zarucchi (1993) como un endemismo; sin embargo, no ha sido posible evaluarlo, ni asignarle una categoría.

\section{Miconia terborghii Wurdack}

Publicación: Phytologia 23(5): 483-484. 1972.

Colección tipo: T.R. Dudley 10890

Herbarios: NA, US.

Nombre común: D esconocido.

Registro departamental: CU.

Regiones Ecológicas: $\mathrm{BPM}, \mathrm{BMHM}$; 2663- $2700 \mathrm{~m}$.

SINAN PE: Sin registro.

Herbarios peruanos: Ninguno.

Observaciones: Este taxón fue considerado por Brako \& Zarucchi (1993) como un endemismo; sin embargo, no ha sido posible evaluarlo, ni asignarle una categoría.

148. Miconia thaminantha Wurdack subsp. huanucensis Wurdack

Publicación: Phytologia 23(5): 495. 1972. Colección tipo: T.R. Dudley 13187

Herbarios: NA, US.

Nombre común: D esconocido.

Registro departamental: HU.

Regiones Ecológicas: BMHP; $1290 \mathrm{~m}$.

SINANPE: RCS

Herbarios peruanos: Ninguno. 
Observaciones: Árbol conocido de la cuenca del Pachitea. Este taxón fue considerado por Brako \& Zarucchi (1993) como un endemismo; sin embargo, no ha sido posible evaluarlo, ni asignarle una categoría.

\section{Miconia thaminanthaWurdack subsp. thaminantha}

\author{
Publicación: \\ Colección tipo: T.R. Dudley 10531 \\ Hemarios: NA, US. \\ Nombre común: D esconocido. \\ Registro departamental: CU. \\ Regiones Ecológicas: BMHM; $1800 \mathrm{~m}$. \\ SINAN PE: Sin registro. \\ Herbarios peruanos: Ninguno.
}

Observaciones: Árbol conocido de la cuenca del Apurímac. Este taxón fue considerado por Brako \& Zarucchi (1993) como un endemismo; sin embargo, no ha sido posible evaluarlo, ni asignarle una categoría.

\section{Miconia thysanophylla Wurdack}

$$
\text { CR, B1a }
$$

Publicación: Brittonia 40(1): 13-14. 1988.

Colección tipo: R. Kayap 1414

Herbarios: MO, US.

Nombre común: D esconocido.

Registro departamental: AM.

Regiones Ecológicas: BHA; 240-600 m.

SINAN PE: ZRSC

Henbarios peruanos: ZRSC.

Observaciones: Árbol conocido sólo de la cuenca del Cenepa, hoy en la Zona Reservada Santiago-Comaina. Brako \& Zarucchi (1993) no indicaron su distribución restringidaal Penú. No havuelto a ser recolectada desde 1974, pero probablemente colecciones de herbanio adicionales realizadas los últimos años en la zona incluyan a esta especie.

\section{Miconia tini Triana}

Publicación: Trans. Linn. Soc. London 28(1): 127. [1872] 1871.

Colección tipo: J. D ombey s.n.

Herbarios: $\mathrm{P}$.

Nombre común: Tiri.

Registro departamental: HU, JU.

Regiones Ecológicas: Sin datos; altitud desconocida.

SINAN PE: Sin registro.

Herbarios peruanos: Ninguno.

Observaciones: Este taxón fue considerado por Brako \& Zarucchi (1993) como un endemismo; sin embargo, no ha sido posible evaluarlo, ni asignarle una categoría.

152. Miconia trichogona J.F. Macbr.

Publicación: Publ. Field Columbian Mus., Bot. Ser. 4(8): 187. 1929.

Colección tipo: J.F. Macbride 5178

Herbarios: F, US.

Nombre común: D esconocido.

Registro departamental: HU.

Regiones Ecológicas: BMHM; 1829 m.

SINAN PE: Sin registro.

Herbarios peruanos: Ninguno.
Observaciones: Este taxón fue considerado por Brako \& Zarucchi (1993) como un endemismo; sin embargo, no ha sido posible evaluarlo, ni asignarle una categoría.

\section{Miconia urbaniana Cogn.}

Publicación: Bot. Jahrb. Syst. 42: 139. 1908.

Colección tipo: A. Weberbauer 5012

Herbarios: B.

Nombre común: D esconocido.

Registro departamental: CU, SM.

Regiones Ecológicas: BMHP; 1300 m.

SINAN PE: Sin registro.

Hembarios peruanos: Ninguno.

Observaciones: Este taxón fue considerado por Brako \& Zarucchi (1993) como un endemismo; sin embargo, no ha sido posible evaluarlo, ni asignarle una categoría.

\section{Miconia uvida Wurdack}

Publicación: Phytologia 9(7): 418. 1964. Colección tipo: J.J. Wurdack 2153

Herbarios: USM.

Nombre común: Desconocido.

Registro departamental: AM, LO.

Regiones Ecológicas: BHA; altitud desconocida.

SINAN PE: Sin registro.

Hemarios penuanos: USM (isotipo citado).

Observaciones: Este arbusto fue descrito de una planta recolectada en 1962, de la cuenca del Marañón, antes del Pongo de Manseriche y por tanto en el departamento de Amazonas y no Loreto como se le atribuye. Sin embargo, por estar tan cerca al límite departamental se la considera en ambos departamentos.

\section{Miconia vargasii Wurdack}

Publicación: Phytologia 23(5): 498-499. 1972.

Colección tipo: C. Vargas C. 2942

Herbarios: US.

Nombre común: D esconocido.

Registro departamental: CU.

Regiones Ecológicas: BPM; 3400 m.

SINAN PE: Sin registro.

Hembarios peruanos: Ninguno.

Observaciones: Arbusto conocido solamente de la cuenca del Urubamba, muy cerca del Santuario Histórico Machu Picchu. No ha sido posible evaluarlo, ni asignarle una categoría.

156. Miconia vitiflora J.F. Macbr.

Publicación: Publ. Field Columbian Mus., Bot. Ser. 4(8): 187. 1929.

Colección tipo: J.F. Macbride 5165

Herbarios: F, US.

Nombre común: D esconocido.

Registro departamental: HU, PA.

Regiones Ecológicas: BMHM; 1829 m.

SINAN PE: Sin registro.

Herbarios peruanos: Ninguno. 
Observaciones: Este taxón fue considerado por Brako \& Zarucchi (1993) como un endemismo; sin embargo, no ha sido posible evaluarlo, ni asignarle una categoría.

\section{Miconia weberbaueri Cogn.}

Publicación: Bot. Jahrb. Syst. 42: 144. 1908.

Colección tipo: A. Weberbauer 3396

Herbarios: B.

Nombre común: D esconocido.

Registro departamental: HU.

Regiones Ecológicas: BMHM; $2500 \mathrm{~m}$.

SINAN PE: Sin registro.

Hemarios peruanos: Ninguno.

Observaciones: Este taxón fue considerado por Brako \& Zarucchi (1993) como un endemismo; sin embargo, no ha sido posible evaluarlo, ni asignarle una categoría.

\section{Miconia wolfei Wurdack}

Publicación: Phytologia 23(5): 486. 1972.

Colección tipo: F. Wolfe 12429

Herbarios: NA, US.

Nombre común: D esconocido.

Registro departamental: HU.

Regiones Ecológicas: BMHM; 1880$2200 \mathrm{~m}$.

SINANPE: RCS

Herbarios peruanos: RCS.

Observaciones: Arbusto de sotobosque que se conoce de una localidad en la Reserva Comunal Sira. No ha sido posible evaluarlo, ni asignarle una categoría.

\section{Miconia woytkowskii Wurdack}

\section{EN, Bla}

Publicación: Phytologia 16(3): 178. 1968.

Colección tipo: F. Woytkowski 34407

Herbarios: UC, US.

Nombre común: D esconocido.

Registro departamental: HU, UC.

Regiones Ecológicas: BHA; 260- 500 m.

SINAN PE: Sin registro.

Herbarios peruanos: Ninguno.

Observaciones: Esta especie arbustiva se conoce del límite entre los Departamentos de Huánuco y Ucayali, en la cuenca del Aguaytía. A parentemente no ha vuelto a ser recolectada desde la década de 1980. Las poblaciones conocidas delas recolectas crecían en bordes debosque, por lo que cambios en esos ambientes podría haberlas afectado.

\section{Microlicia sphagnicola Gleason}

\section{DD}

Publicación: Bull. Torrey Bot. Club 58: 215. 1931.

Colección tipo: E.P. Killip \& A.C. Smith 25680

Herbarios: GH, US.

Nombre común: D esconocido.

Registro departamental: PA.

Regiones Ecológicas: BMHM; 1700$2050 \mathrm{~m}$.

SINANPE: Sin registro.

Hemarios peruanos: Ninguno.
Observaciones: Arbusto descrito de una planta recolectada en la cuenca del Pichis, a lo largo de una trocha de arrieros y que se consideraba, en 1929, como parte de Junín, pero hoy en Pasco. Se conoce de poblaciones naturalmente fragmentadas, puesto que habita zonas pantanosas, de turberas de Sphagnum. Podría estar en otras localidades con esas características. Los ambientes conocidos están amenazados por la extracción de esas turberas.

\section{Microlicia weddellii Naudin}

\section{DD}

Publicación: Ann. Sci. Nat., Bot., ser. 3, 12(10): 251. 1849.

Colección tipo: H. Weddell 4650

Herbarios: $P$.

Nombre común: D esconocido.

Registro departamental: PU.

Regiones Ecológicas: BMHM; 1800$2600 \mathrm{~m}$.

SINAN PE: Sin registro.

Herbarios peruanos: Ninguno.

Observaciones: Arbusto conocido de dos poblaciones en la vertiente oriental de Puno. Al parecer, no havuelto a ser recolectado desde 1902. Podría estar representado en la flora de Bolivia.

\section{Monochaetum subglabrum Gleason}

\section{DD}

Publicación: Bull. Torrey Bot. Club 58: 220. 1931.

Colección tipo: E.P. Killip \& A.C. Smith 22325

Herbarios: NY, US.

Nombre común: D esconocido.

Registro departamental: AY, HV, JU, SM. Regiones Ecológicas: BMHM; $1500 \mathrm{~m}$.

SINANPE: Sin registro.

Herbarios peruanos: Ninguno.

Observaciones: Arbusto conocido de la cuenca del río Apurímac, donde ocupaba matorrales en ladera. Al parecer, no ha vuelto a ser recolectada desde 1929.

\section{Mounini exadenia Morley}

\section{DD}

Publicación: Fl. Neotropica 15: 136. 1976. Colección tipo: E.P. Killip \& A.C. Smith 28197

Herbarios: US.

Nombre común: D esconocido.

Registro departamental: LO.

Regiones Ecológicas: BHA; $135 \mathrm{~m}$.

SINANPE: Sin registro.

Herbarios peruanos: Ninguno.

Observaciones: Árbol conocido de una localidad, en la cuenca del Huallaga, donde fue recolectado en 1929, en bosques densos. No se conoce detalles de su hábitat. 


\section{Salpinga ciliata Pilg.}

DD

Publicación: Verh. Bot. Vereins Prov. Brandenburg 47: 167. 1905.

Colección tipo: E.H.G. Ule 6743

Herbarios: $B$.

Nombre común: D esconocido.

Registro departamental: LO.

Regiones Ecológicas: BMHP; $800 \mathrm{~m}$.

SINAN PE: Sin registro.

Herbarios peruanos: Ninguno.

Observaciones: Subarbusto conocido, al parecer, sólo de la localidad original, en la cuenca del Mayo, donde fue recolectado en 1903.

\section{Salpinga penuviana (Cogn.) Wurdack}

$$
\text { EN, Blab(iii) }
$$

Publicación: Phytologia 21(6): 354. 1971.

Colección tipo: A. Weberbauer 4645

Herbarios: B.

Nombre común: Desconocido.

Registro departamental: HU, SM.

Regiones Ecológicas: BMHP; $1290 \mathrm{~m}$.

SINANPE: RCS

Herbarios peruanos: Ninguno.

Observaciones: Bejuco conocido de dos localidades, en el oriente del país. Esta especie fue descrita de una planta recolectada en la cuenca del Mayo en 1904, aunque la localidad exacta fue atribuida erroneamente a Loreto. Una población de esta especie fue registrada en el área que hoy ocupa la Reserva Comunal del Sira.

\section{Tibouchina brevisepala Cogn.}

Publicación: Bot. Jahrb. Syst. 42: 135. 1908.

Colección tipo: A. Weberbauer 4965

Herbarios: B.

Nombre común: Desconocido.

Registro departamental: AP, CU.

Regiones Ecológicas: BPM; altitud desconocida.

SINAN PE: Sin registro.

Herbarios peruanos: Ninguno.

Observaciones: Estetaxón fue considerado por Brako \& Zarucchi (1993) como un endemismo; sin embargo, no ha sido posible evaluarlo, ni asignarle una categoría.

\section{Tibouchina echinata (Ruiz \& Pav.) Cogn.}

Publicación: Monogr. Phan. 7: 266. 1891. Colección tipo: H. Ruiz \& J. Pavón s.n. Herbarios: MA.

Nombre común: D esconocido.

Registro departamental: HU, PA.

Regiones Ecológicas: BMHM; 1600$1670 \mathrm{~m}$.

SINANPE: Sin registro.

Herbarios peruanos: Ninguno.

Observaciones: Este taxón fue considerado por Brako \& Zarucchi (1993) como un endemismo; sin embargo, no ha sido posible evaluarlo, ni asignarle una categoría.
168. Tibouchina fulvipilis Cogn.

Publicación: Bot. Jahrb. Syst. 50(Beibl. 111): 31-32. 1913.

Colección tipo: A. Weberbauer 5625

Hembarios: B, US.

Nombre común: D esconocido.

Registro departamental: AY.

Regiones Ecológicas: BPM; $2800 \mathrm{~m}$.

SINAN PE: Sin registro.

Herbarios peruanos: Ninguno.

Observaciones: Arbusto conocido sólo de la localidad original, en la cuenca del Apurímac. No ha sido posible evaluarlo, ni asignarle una categoría.

\section{Tibouchina hutchisonii Wurdack}

\section{DD}

Publicación: Phytologia 14(5): 258-259. 1967.

Colección tipo: P.C. Hutchison et al. 6034

Herbarios: UC, US; USM.

Nombre común: D esconocido.

Registro departamental: UC.

Regiones Ecológicas: BHA; altitud desconocida.

SINANPE: Sin registro.

Herbarios peruanos: USM (isotipo citado).

Observaciones: Arbusto conocido de una localidad al sur del Parque Nacional Condillera Azul. Esta localidad fue citada por error como ubicada en el departamento de San Martín (Wurdack, 1967), pero en realidad corresponde a Ucayali. Aparentemente no ha vuelto a ser recolectada desde 1964 y se desconoce el estado de sus poblaciones.

\section{Tibouchina incanum Gleason}

\section{VU, Bla}

Publicación: Amer. J. Bot. 26: 634. 1939. Colección tipo: E.K. Balls 6817

Hembarios: US.

Nombre común: D esconocido.

Registro departamental: CU.

Regiones Ecológicas: BMHM; $1524 \mathrm{~m}$.

SINANPE: SHMP

Herbarios peruanos: Ninguno.

Observaciones: Arbusto conocido de unas pocas poblaciones, sólo de la cuenca del Urubamba, donde habita el Santuario Histórico Machu Picchu. Ha sido registrada en diferentes años.

\section{Tibouchina mariae Wurdack}

\section{VU, Bla}

Publicación: Phytologia 13(2): 65-66. 1966. Colección tipo: J.J. Wurdack 632

Hemarios: US; USM!

Nombre común: D esconocido.

Registro departamental: AM, CA.

Regiones Ecológicas: BMHM; 2200$2800 \mathrm{~m}$.

SINANPE: PNC

Hemarios penuanos: CPUN (4), HAO (1), USM (isotipo). 
Observaciones: Arbusto conocido de varias localidades, en el nororiente del país, incluyendo poblaciones en el Parque Nacional Cutervo. Esta especie ha sido recolectada también en Cerros Calla Calla, unazona que alberga varios endemismos, pero no recibe protección.

\section{Tibouchina pulchemima Gleason}

\section{DD}

Publicación: Bull. Torrey Bot. Club 54: 26. 1927.

Colección tipo: F.W. Pennell 13971

Herbarios: PH.

Nombre común: D esconocido.

Registro departamental: CU.

Regiones Ecológicas: BMHM; 2100$2400 \mathrm{~m}$.

SINANPE: Sin registro.

Herbarios peruanos: Ninguno.

Observaciones: Especie arbustiva conocida de unos pocos registros provenientes de los límites suroccidentales del Parque Nacional Manu.

\section{Tibouchina repens Wurdack}

\section{DD}

Publicación: Phytologia 5(2): 55-56. 1954.

Colección tipo: H.A. Allard 22082

Herbarios: US.

Nombre común: D esconocido.

Registro departamental: $\mathrm{HU}$.

Regiones Ecológicas: BHA; $400 \mathrm{~m}$.

SINANPE: Sin registro.

Herbarios peruanos: Ninguno.

Observaciones: Arbusto conocido de una localidad al suroeste del Parque Nacional Cordillera Azul. Esta localidad fue citada por error, como ubicada en el departamento de San Martín (Wurdack, 1954), pero en realidad corresponde a Huánuco. Al parecer, no ha vuelto a ser recolectada desde 1949.

\section{Tibouchina sandiensis Wurdack}

\section{DD}

Publicación: Phytologia 14(5): 259-260. 1967.

Colección tipo: R. Ferreyra 16677

Herbarios: US; USM.

Nombre común: D esconocido.

Registro departamental: PU.

Regiones Ecológicas: BMHM; 1800$1900 \mathrm{~m}$.

SINAN PE: Sin registro.

Herbarios penuanos: USM (isotipo citado).

Observaciones: Arbusto conocido de dos poblaciones en la cuenca alta del Inambari. Aparentemente no ha vuelto a ser recolectada desde 1966.

\section{Tibouchina saxosa Gleason}

Publicación: Phytologia 1(3): 135-136. 1935.

Colección tipo: F.W. Pennell 13992

Herbanios: GH.

Nombre común: D esconocido.

Registro departamental: AY, CU, HU, HV. Regiones Ecológicas: BMHM; 2000$2800 \mathrm{~m}$.

SINANPE: SHMP

Henbarios penuanos: USM?.

Observaciones: Este taxón fue considerado por Brako \& Zarucchi (1993) como un endemismo; sin embargo, no ha sido posible evaluarlo, ni asignarle una categoría.

\section{Tibouchina wasshausenii Wurdack}

\section{DD}

Publicación: Brittonia 40(1): 7, f. 1. 1988. Colección tipo: D. Wasshausen \& A. Salas 1209 Henbarios: US.

Nombre común: D esconocido.

Registro departamental: PU.

Regiones Ecológicas: BMHP; $1200 \mathrm{~m}$.

SINAN PE: Sin registro.

Herbarios peruanos: Ninguno.

Observaciones: Arbusto conocido sólo de la localidad original, en la cuenca alta del río Tambopata. Probablemente, esté representada en el Parque Nacional Bahuaja-Sonene. El escaso conocimiento que hay sobre esta especie pueda deberse a las características de su hábitat y por crecer en una zona poco herborizada.

\section{Tibouchina weberbaueri Cogn.}

Publicación: Bot. Jahrb. Syst. 42: 136. 1908. Colección tipo: A. Weberbauer 5002

Hemanios: B.

Nombre común: D esconocido.

Registro departamental: $\mathrm{CU}$.

Regiones Ecológicas: BMHM; $1700 \mathrm{~m}$.

SINANPE: Sin registro.

Herbarios peruanos: Ninguno.

Observaciones: Este taxón fue considerado por Brako \& Zarucchi (1993) como un endemismo; sin embargo, no ha sido posible evaluarlo, ni asignarle una categoría.

\section{Tococa gonopteraGleason}

$$
\text { EN, Bla }
$$

Publicación: Bull. Torrey Bot. Club 58(4): 247-248. 1931.

Colección tipo: E.P. Killip \& A.C. Smith 28092

Henbarios: NY, US.

Nombre común: D esconocido.

Registro departamental: LO, SM.

Regiones Ecológicas: BHA; 135-180 m.

SINANPE: Sin registro.

Herbarios peruanos: USM (1).

Observaciones: Arbusto conocido de varias localidades, en la cuenca del nó Huallaga. Tiene afinidades evolutivas con Tococa quadrialata del Perú y Bolivia (Michelangeli, 2000a). Las localidades más extremas están separadas por aproximadamente $200 \mathrm{~km}$ en línea recta. 


\section{Topobea pascoensis Wurdack}

DD

Publicación: Brittonia 40(1): 14-15. 1988.

Colección tipo: R.B. Foster 7745

Herbarios: F, TEX, US.

Nombre común: D esconocido.

Registro departamental: PA.

Regiones Ecológicas: BMHM; 1900 m.

SINAN PE: PNYC

Herbarios peruanos: Ninguno.

Observaciones: Árbol erecto o decumbente conocido de una localidad, en la cuenca del río Palcazú, en el Parque Nacional Yanachaga-Chemillén. No ha vuelto a ser recolectada desde 1984; probablemente con mayores exploraciones en las cimas de cordilleras pueda adicionarse información sobre su distribución.

\section{Triolena allardii (Wurdack) Wurdack}

DD

Publicación: Phytologia 31(6): 493. 1975. Colección tipo: H.A. Allard 20510

Henbarios: US.

Nombre común: D esconocido.

Registro departamental: HU.

Regiones Ecológicas: BMHM, BMHP; 625- $1600 \mathrm{~m}$.

SINAN PE: PNTM

Herbarios peruanos: Ninguno.

Observaciones: Arbusto conocido de unas pocas poblaciones en la cuenca del Huallaga. La localidad original fue citada por error, como ubicada en el departamento de San Martín (Wurdack, 1964), pero en realidad corresponde a Huánuco. Ha sido registrada en diferentes años y es probable que se halle representada en el Parque Nacional Tingo María.

\section{Votomita pubescens Morley}

\section{EN, Bla}

Publicación: Ann. Missouri Bot. Gard. 75(2): 556. 1985.

Colección tipo: R. Lao 22

Herbarios: $F$.

Nombre común: Lanza caspi.

Registro departamental: LO.

Regiones Ecológicas: BHA; 120-140 m.

SINANPE: Sin registro.

Herbarios peruanos: AMAZ (1).

Observaciones: Esta especie arbórea se conoce solamente de la cuenca del río Ucayali; varios ejemplares de herbario, recolectados en los 1970, provienen de la población del Arboreto Jenaro Herrera (Spichiger et al., 1990).

182. Wurdastom dudleyi (Wurdack) B. Walln.

\section{DD}

Publicación: Ann. Naturhist. Mus. Wien, Ser. B, Bot. Zool. 98(Suppl.): 461. 1996.

Colección tipo: M.T. Madison 10101

Herbarios: US.

Nombre común: D esconocido.

Registro departamental: $\mathrm{CU}$.

Regiones Ecológicas: BMHM; 1730 m.

SINANPE: Sin registro.

Herbarios peruanos: Ninguno.

Observaciones: Árbol conocido, al parecer, sólo de una localidad en el valle del Apurímac. No se conocen registros posteriores a 1970. Podría estar representado en el Parque Nacional Otishi. 


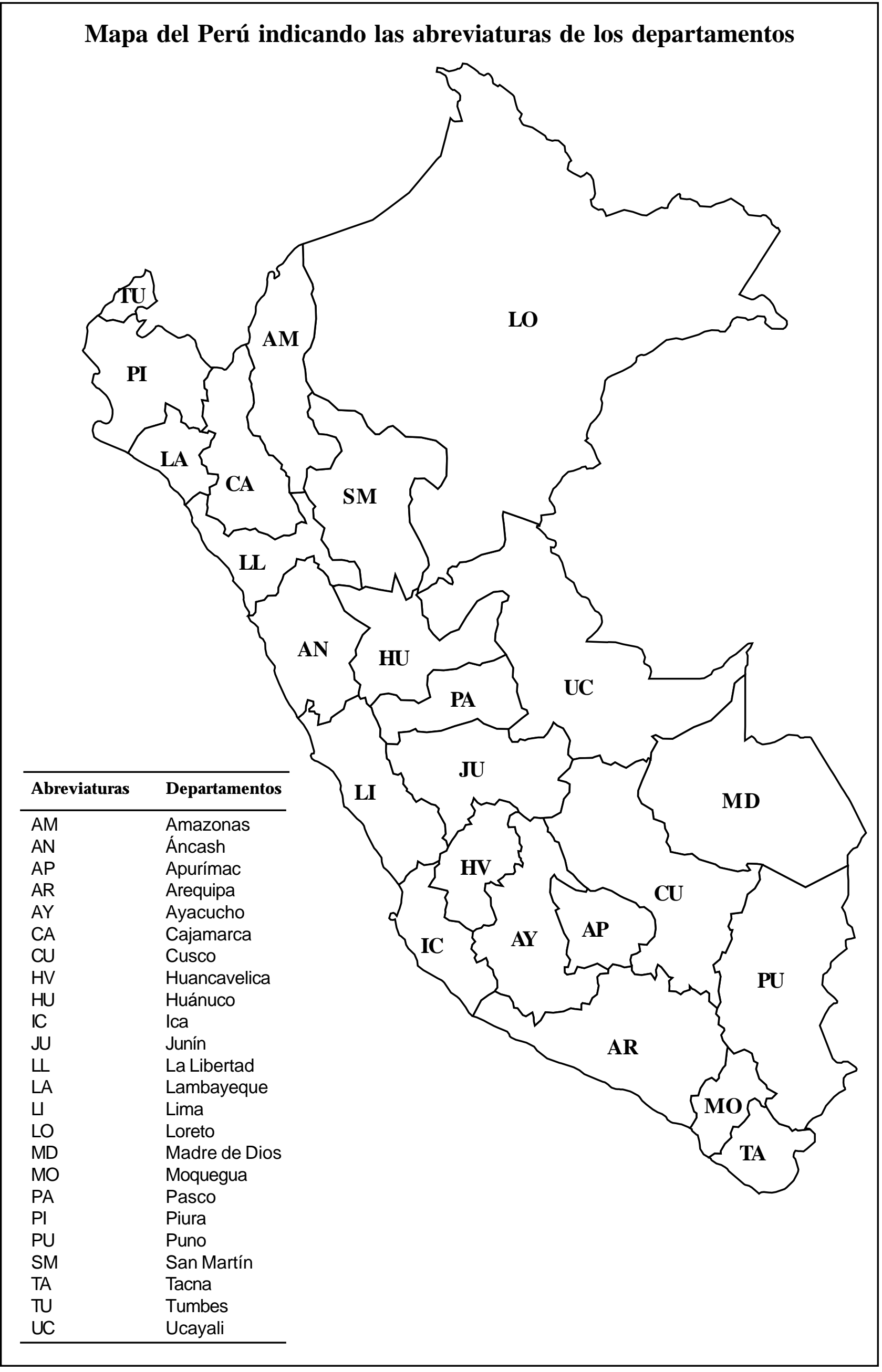

